\title{
How Smart is the Grid?
}

\author{
Ermanno Lo Cascio ${ }^{1 *}$, Luc Girardin ${ }^{1}$, Zhenjun $\mathrm{Ma}^{2}$ and François Maréchal ${ }^{1}$ \\ ${ }^{1}$ Industrial Process and Energy Systems Engineering (IPESE) Group, École Polytechnique Fédérale de Lausanne, EPFL Valais- \\ Wallis, Sion, Switzerland, ${ }^{2}$ Sustainable Buildings Research Centre (SBRC), University of Wollongong, Wollongong, NSW, Australia
}

Ancient Romans called urbs the set of buildings and infrastructures, and civitas the Roman citizens. Today instead, while the society is surfing the digital tsunami, urbs and civitas tend to become much closer, almost merging, that we might attempt to condensate these into a single concept: smart grid. Internet of things, artificial intelligence, blockchain, and quantum cryptography are only a few of the technologies that are likely to contribute to determining the final portrait of the future smart grid. However, to understand the effective sustainability of complex grids, specific tools are required. To this end, in this article, a new taxonomic framework has been developed starting from a general analysis of the emerging solutions, identifying intersectoral synergies and limitations with respect to the 'smart grid' concept. Finally, from the scenario portrayed, a set of issues involving engineering, regulation, security, and social frameworks have been derived in a theoretical fashion. The findings are likely to suggest the urgent need for multidisciplinary cooperation to address engineering and ontological challenges gravitating around the smart grid

\section{OPEN ACCESS}

Edited by:

Farhad Taghizadeh-Hesary,

Tokai University, Japan

Reviewed by:

Amr Munshi,

Umm al-Qura University, Saudi Arabia Antonio Moreno-Munoz, University of Cordoba, Spain

*Correspondence:

Ermanno Lo Cascio ermannolocascio@gmail.com

Specialty section: This article was submitted to Sustainable Energy

Systems and Policies,

a section of the journal

Frontiers in Energy Research

Received: 03 December 2020

Accepted: 07 June 2021

Published: 24 June 2021

Citation:

Lo Cascio E, Girardin L, Ma Z and Maréchal $F$ (2021) How Smart is the

Grid?

Front. Energy Res. 09:637447. doi: 10.3389/fenrg.2021.637447 concept.

Keywords: cascading failures, Internet of Things, resilience, domino effect, smart grid generations, integrated energy systems, planetary grids

\section{INTRODUCTION}

\subsection{Yesterday}

'DC power systems dominated in the 1870s and 1880s. Small systems were sold to factories around the world, both in urban areas, and remote undeveloped areas for industrial/mining use. Thomas Edison, Charles Brush, and Werner von Siemens lead the industry in DC systems. DC systems powered factories and small downtown areas but did not reach $95 \%$ of residents. Electric lighting was a luxury found only in hotels and other businesses as well as in the mansions of people like George Westinghouse and J.P. Morgan.' The first alternating current power grid was installed in 1886 in Massachusetts (Edison Tech Center, 2013). During the 20th century local grids grew over time and become slowly interconnected most for economic and reliability reasons. During the 60s, industrialized countries were characterized by large, technological mature and highly interconnected power grids, constituted by numerous centralized generation power stations. Smart grid technologies emerged during the $80 \mathrm{~s}$ when earlier attempts to employ electronic control, metering and monitoring have been made. In 2000, Italy's deployed the first project to connect 27 million of homes using smart meters connected via low bandwidth power line communication (U.S. Department of Energy, 2007). Then, the digital tsunami arrived.

\subsection{Today}

In the past two years, the $90 \%$ of the data in the world were created and 2.5 quintillion bytes of data are created every day (Marr, 2018). This is thanks to the digital technologies that have also made expand the sectorial conceptual borders, especially for the smart grid archetype, where end-users and complementary sectors like transportation, tends to be intimately linked. This is also thanks to the 
advances in computing power and efficiency that have enabled more powerful and sophisticated analytic, such as artificial intelligence and automation (IEA, 2017). According to the International Energy Agency (IEA, 2020), 'digital technologies can help make the energy system more intelligent, reliable and sustainable, whereas it is also raising security and privacy risks, changing market.' However, if we put ourselves in a metaperspective and, if we reframe this scenario, we might also convince that the market is changing the digitalization, making the energy system more connected for sure. But, intelligent? Resilient? Sustainable? The exuberant availability of electronic devices (Sovacool and Del Rio, 2020), for instance, seems to be the proof of the presence of an uncontrolled commercial speculative pool whose inertia, if not properly addressed, would likely affect the evolution of the smart grid, exchanging threats with strengths. Thus, from this scenario, it emerges the desire of attempting answering the question: 'how smart is the grid?.' However, to this aim, first we need to delineate what the 'grid' refers to, and what 'smart' stands for. Factually, from today's perspective, the term 'grid' assumes a broader meaning involving not only the electrical transmission network, but also other energy carriers (thermal, natural gas, etc.) as they have become a fundamental part of the grid, and their operations, services delivery, and management tend to be highly interdependent, e.g., smart thermal grids (Lund et al., 2014) and gas grids (Lund et al., 2017). On the other hand, the term 'smart' suffers of a high semantic inflation, which commonly pushes us to exchange the 'smartness' of the 'grid' with its level of automation, while the level of automation might not always be synonymous of smartness - in the most general sense of the term. Thus, in this study, we associate the term 'smart' to the final objective of increasing the life-quality of the community by creating a holistically sustainable energy system and service. Given this premise, at the state-of-the-art, different scientists have provided structured discussions for the topic. Some authors contributed by reviewing the issue through a vertical approach, thus providing an in-depth review of a given technological sub-domain of the smart grid framework. In fact, from one hand, for instance, Tu et al. (2017) reviewed the big data issues for the smart grid, and thoroughly discussed theoretical and practical applications, with reference to the power grid. Sovacool and Del Rio (2020) examined the technologies for smart homes in Europe, and discussed concepts, benefits, risks and policies. In (Reka and Dragicevic, 2018) and in (Stojkoska and Trivodaliev, 2017), the most significant research studies on the application of the Internet of Things technologies for the smart grid framework were reviewed. On the other hand, instead, some authors reviewed the problem from a broader perspective. Dileep (2020), for instance, provided an extensive survey of the domain, and thoroughly discussed technologies and applications, with a particular focus on the electrical grid. Similarly, Tuballa and Abundo (2016) presented an overview of the smart grid, and discussed its features, functionalities and characteristics. Bibri and Krogstie (2017b) provided a comprehensive overview of the domain evaluating the foundations and assumptions of the smart (and) sustainable cities. Here, the authors identified the need to develop a theoretical and practically convincing framework for strategic sustainable urban development. The level of complexity of the smart grid domain, specially due to the ICT penetration, make it difficult to understand the effective sustainability of the technological configuration adopted. For this reason, the authors identify the need to outline a preliminary assessment framework. To this aim, in the presented paper, a different reviewing approach has been employed. In fact, while these last studies provide a review whose conceptual borders involve a given domain and/or a given issue of the framework, we attempt to answer to ontological questions by employing a broader analytical approach, using a multi-domain anthology as a tool, thus embracing those technologies, issues and aspects that are likely to come into play in the definition of the portrait of the future smart grid. As outcome of this review process, we obtain and propose a preliminary socio-technological taxonomic model which is likely to begin the definition of a rigorous labeling protocol to assess - in a objective way - the smartness of a generic grid. Precisely, Figure 1 represents the study approach employed in this research to outline the taxonomic model to assess the sustainability of the grid, and to derive mid and long term actions. To this aim, a complete collection of technologies is constructed (smart grid anthology). This last is employed to drive a higher level process, where a systematic and critical analysis is conducted, working on the blurry line between synergies and complexity emerging from novel solutions and/or domains interdependencies. Finally, starting from the new portrait of the smart grid, we attempt to explicitly re-frame the fundamental and implicit values of the smart grid concept (ontology). In the last part of the paper, we identify possible mid and long-term actions for a proper smart grid (smart energy system) design, thus, for a sustainable urban system creation.

\section{TECHNOLOGICAL FRAMEWORK AND EMERGING TRENDS}

In this section a general analysis of the technological framework and the emerging trends for the smart grid domain is provided. The analytical approach employed embraces the smart grid domain concept from a broader perspective, thus coherently considering interdisciplinary aspects and technological solutions.

\subsection{Internet of Things}

"The Internet of Things (loT), Internet of Everything (loE) and Internet of Nano Things are new approaches for incorporating the Internet into the generality of personal, professional and societal life. The term 'Internet of Things' or 'Internet of Objects' has come to represent electrical or electronic devices, of varying sizes and capabilities, that are connected to the Internet. The scope of the connections is ever broadening to beyond just machine-to-machine communication." Miraz et al. (2015). Reka and Dragicevic (2018) provided a review of the ongoing research contextualizing - in a comprehensive fashion - the role of IoT within the smart grid framework. This research outlines a technological perspective according to which the IoT evolution needs further developments at architectural and 


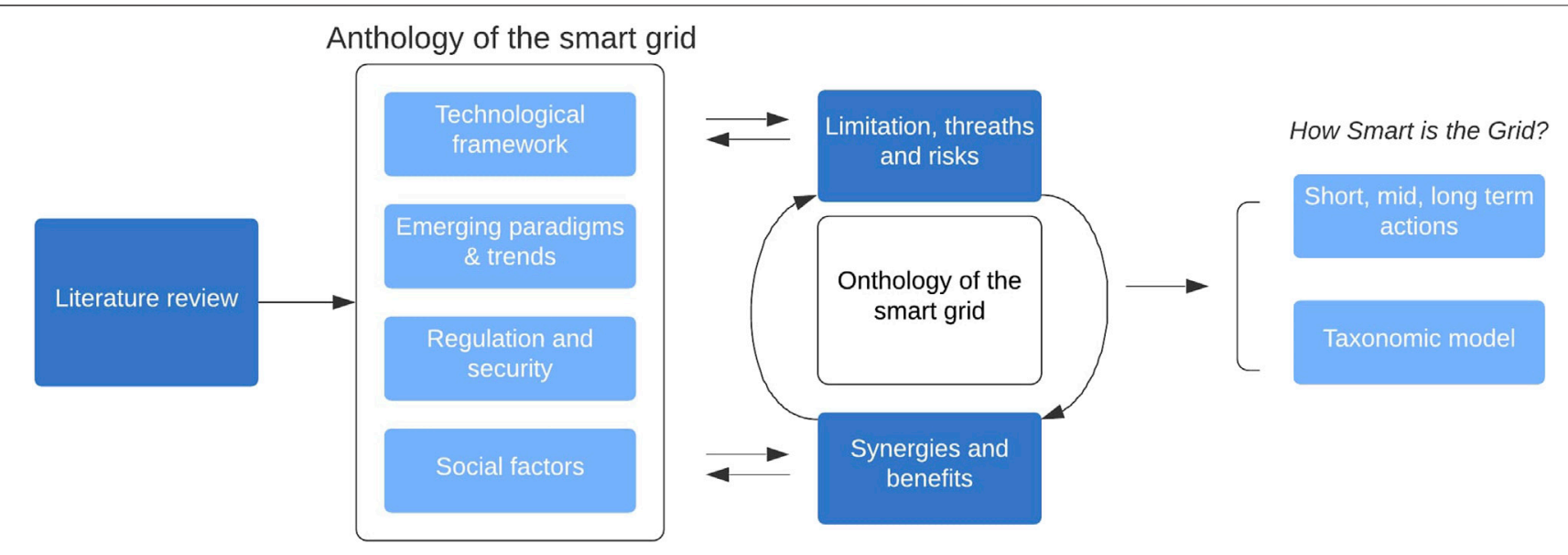

FIGURE 1 | Study methodology.

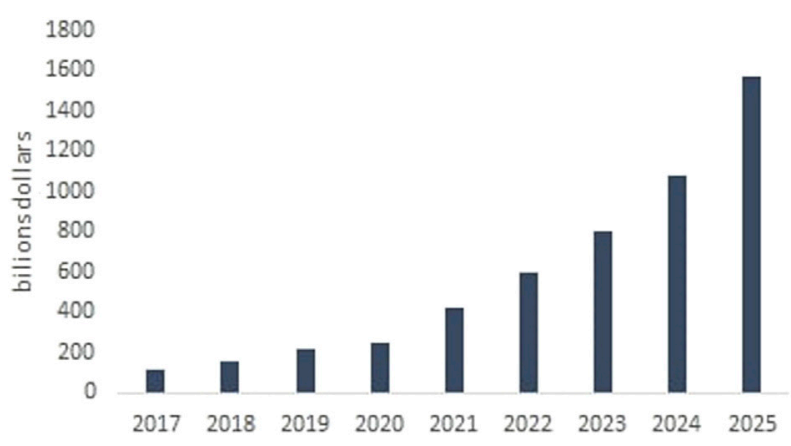

FIGURE 2 | Forecast end-user spending on loT solutions worldwide from 2017 to 2025. Derived from Statista (2020).

standardization levels. Similarly, Zhou et al. (2016) provided an overview of the smart home energy management systems, highlighting the need for further conceptual, technological and architectural upgrades to welcome and better exploit renewable energy technologies in the residential and tertiary sector. Schieweck et al. (2018), analyzed the e-panorama for smart homes focusing on indoor air quality and people's perception. From the context pictured by this review study, it clearly emerges that there is a great margin of improvement at different levels, especially referred to the human adaptation and interaction with the smart home environment. But, can IoTs technologies help reduce energy consumption by means of optimal control of the heating, ventilation, and air conditioning (HVAC) system? It depends on the context considered and the "point of view". In fact, if we look at the building level, for instance, Lomas et al. (2018) recognized moderated quality evidence that smart thermostats may not save energy compared to a non-smart thermostat. Even, for a case study in the United States, the energy demand increased by $2-4 \%$ with self-learning algorithms, compared with conventional on-off control. However, if we look at the system level (generation, distribution, end-users) the effective energy impact originated by the use of smart thermostats or, in general, by in-home display for HVAC control, might be sensibly different. In fact, smart thermostat can participate in utility demand response programs King (2018), thanks to the connectivity enabled among the system's players, thus representing a strategic element of the "puzzle" to unlock sustainable operations, without affecting the users' comfort, through peak shaving and demand-side management, specially when aggregated across different homes (Unger, 2017). Furthermore, Wang (2018) glimpsed a great opportunity behind smart in-home devices if these are capable to transact energy for peer-to-peer applications or with the grid. Generally speaking, it is likely to be that every case, every building, has its own characteristics in terms of energy-saving potential and controllability which are mainly linked to the boundary conditions (weather, etc.), the envelope thermophysical characteristics, HVAC type and control and, finally, occupancy profiles and human factors. The peculiarities of every building are probably the reason that brings Balta-Ozkan et al. (2013) to identify a need for a holistic view for the design and delivery of smart home services, enabling tailored solutions for householders, appropriate to the context. As shown in Figure 2, the IoT global market for end-users is expected to grow up to 1.6 trillion in US dollars by 2025 (Statista, 2020). According to Fortune Business Inside (Fortune Business Insights, 2020), the IoT market is expected to reach 1.1 trillion US dollars in 2026. In any case, the sophisticated e-cosmo is actually a multidomain connected, fast-interacting set of physical players (subjects and objects) and every measurable evolution, even its associable economic growth, will be certainly related by this existing sectorial interdependency. In this perspective, an example of technology-to-technology synergy could be represented by the so-called blockchain, which is likely to be a game-changer tool for peer-to-peer energy transactions while it will work as a catalyzer for the IoT market growth. But, the 'evolution equation' of the smart grid is constituted by further several variables that will determine the final picture of the digital era, e.g., innovation in telecommunication, information technologies, regulation and 
anthropological issues. In the following section, we propose an indepth analysis of those further main archetypes involved.

\subsection{Smart Meters}

A meter is expected to have the following capability to be categorized as a 'smart meter' (Alahakoon and Yu, 2015): realtime monitoring; remote and local data accessibility; remote controllability of the meter, for energy cut off; interaction with other meters (gas, water); power quality monitoring and selfanalysis of the device itself; interaction with IoTs.

Bastida et al. (2019), analyzed the energy-saving linked to the electricity sector that could be achieved by employing ICTs in European households. Quantitatively speaking, the contribution of ICTs would range between 0.23 and $3.3 \%$ of the European $\mathrm{CO}_{2}$ reduction target with respect to the $1.5^{\circ} \mathrm{C}$ minimal realistic warming goal at 2100. Smart metering has the potential to revolutionize access to energy consumption data but, as highlighted by (Webborn and Oreszczyn, 2019), a coordinated effort is needed between legislation, funding bodies and researchers to unlock its potential. From this perspective, the European Union issued Directives 2009/72/EC, 2009/73/EC, and Directive 2012/27/EC that insisted on making smart meters available to the majority of households in the EU by 2020 . Italy was the first European country where smart meters rollout started at a large scale, followed by France who started the process in 2013, while in the United Kingdom and Netherlands smart meters have been introduced simultaneously in gas and electricity sectors (Smart Energy International, 2017). Of course, a rollout phase is a complex process, and operators have to deal with different aspects and issues ranging from logistic to complex aspects relative to the social domain, passing through financial and technical challenges. In this sense, the diffusion of a given technology is also intimately linked/bounded by the perception and awareness of people of the technology itself. For example (Chawla and Kowalska-Pyzalska, 2019) investigated the awareness and acceptance level of smart meters among social media users in Poland. Findings suggested a low level of public awareness for this technology for this geographical context, thus limiting the potential benefits that smart meters could generate for them. However, smart meters offer the possibility to read in real time rates and pricing policies, allowing the implementation of demand response programs and demand side management programs. These features are being exploited by utilities in order to achieve energy efficiency, increasing network reliability and produce significant economic savings to the utility and the customer (MinchalaAvila et al., 2016). However, "defining the environment for analyzing streamed big data in real time is not an easy task." (Hasani et al., 2014). There are different approach to this problem and the most promising is the so called Lambda Architecture: a data-processing architecture capable to orchestrate 'big' quantities of data by employing both batch and streamprocessing methods.

\subsection{Blockchain}

Bitcoin, based on blockchain technology, is a cryptocurrency, initially introduced in 2009 by an author whose pseudonym is
Nakamoto (Nakamoto, 2019) and it consists of a verification mechanism, based on distributed consensus and cryptographic security measures. However, as previously mentioned, blockchain is a technology that can be successfully employed also in energy contexts. "UNC Charlotte research team performed a comprehensive worldwide market survey and investigated more than 200 energy blockchain companies and their associated common use cases. The energy blockchain use cases can be categorized as follows" (Cali, 2019):

- Peer-to-Peer Energy Transactions/Trading (33\%),

- Grid Transactions/Utility Scale (25\%),

- Energy Financing/Initial Coin Offering (12\%),

- Labeling/Renewable Energy Attribution and Certification (11\%),

- Electric Vehicle/e Mobility (10\%),

- Others (9\%).

When combined with smart contracts (Zheng et al., 2018), blockchain is capable to enable a decentralized market (Yuan and Wang, 2016). This aspect opens the possibility to realize what has been defined by some scientists as the 'energy democratization' where market dynamics are induced by the community of endusers rather than a centralized organization (Figure 3). Mengelkamp et al. (2018), faced the design aspect of a local decentralized energy market based on blockchain technology. To this aim, the authors realized a proof-of-concept model, including a simulation of a local blockchain-based market where users can bilaterally exchange energy. Andoni et al. (2019), based on the review of 140 blockchain research projects, outlined the key challenges and future outlook for this technology and its application in the energy sector. According to the authors, blockchain represents a promising technology — for different sectors - but several questions need to be addressed in terms of technology scalability, speed, and security. Furthermore, large consensus algorithms need to be further investigated, from a different perspective, with attention to energy consumption and cyber-attacks resilience. In conclusion, from this study, it emerges that, even if they have successfully passed the proofof-concept phase, most projects are still in the early development stage, and thus, further research efforts will have to demonstrate if the technology can reach its technical viability and commercial potential (Andoni et al., 2019). In this perspective, quantum communication will likely help to make a huge step forward in data security thanks to quantum key distribution (Tariq et al., 2019), that involves sending encrypted data as classical bits over networks, while the keys to decrypt the information are encoded and transmitted in a quantum state using qubits, thus enabling, in theory, an ultrasecure communication.

\section{$2.45 G / 6 G$}

$5 \mathrm{G}$ is the fifth-generation wireless technology, whose technological improvements, as defined by the Next Generation Mobile Network Alliance (Osseiran et al., 2014), involve connection speed and capacity, while increasing the latency i.e., the time taken by devices to respond to each other over the wireless network, thus passing from roughly $30 \mathrm{~ms}$ of the 

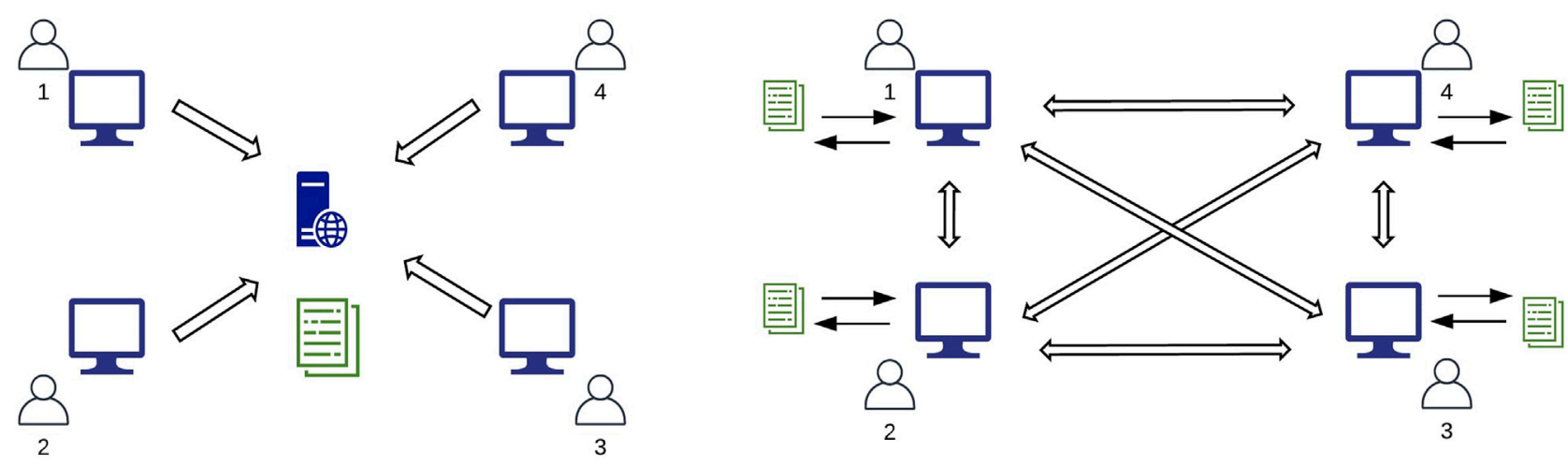

FIGURE 3 | Market structure: current vs. blockchain-based. Derived from PwC Global Power and Utilities (2015).

$4 \mathrm{G}$ to $1 \mathrm{~ms}$. Likely, within the first years of $20^{\prime}, 5 \mathrm{G}$ will start being deployed at a wider level and this little step will affect the society by enabling the connection of billions of devices, affecting every sector, e.g., health, school, and communities, thus increasing the "smartness" of our cities. On the other hand, industries and businesses will be able to gather an enormous amount of information, allowing them to achieve a level of insights capability without precedents. In this perspective, 5G will catalyze the emergence of new technologies such as virtual reality, or services that we cannot even imagine from today's perspective. But, if 5G will enable communication with unprecedented performance, on the other hand, $6 \mathrm{G}$ will drastically shape the communication framework, generating new societal paradigms, thus opening the way to new services such as holographic communication, high precision manufacturing, allowing artificial intelligence achieving its maximum potential (Strinati et al., 2019). From a smart city perspective instead, according to Tariq et al. (2019), with 5G technology energy systems and transportation networks are individually smart. The difference with $6 \mathrm{G}$ is that the control and optimization of energy and transport infrastructure will occur in a holistic and integrated fashion, thus, enabling a truly smart city. In (Saad et al., 2019), the authors outlined a set of possible perspective scenarios for $6 \mathrm{G}$, identifying the complementary technologies and infrastructure that will be likely needed. In this sense, for instance, $6 \mathrm{G}$ will need an integrated terrestrial, airbone and satellite communication network (Cao et al., 2018). Here, as shown in Figure 4, drones will be needed to provide connectivity to those zones where other infrastructures are not sufficiently developed. Furthermore, both drones and terrestrial stations may need connectivity to low orbit satellites and CubSat (NASA CubeSat Launch Initiativel, 2017). As a summary, challenges for the $5 \mathrm{G}$ and $6 \mathrm{G}$ do not only involve the technological side. 5G and $6 \mathrm{G}$ will have to be analyzed and discussed also from a health perspective. Precisely, as reported in (Di Ciaula, 2018), there is an urgent need to undertake further experimental and epidemiologic studies to understand the effect on humans of exposure to these specific radio frequencies.

\subsection{Demand Response and Aggregators}

Historically, energy demand and production matching i.e., load scheduling problem, is one of the main challenges that systems operators have been dealing with. Renewables' penetration has made this issue even more challenging, due to the intermittent nature of these technologies. Today's ICT allows employing demand response energy management systems, whose scope is to control the energy demand to match the available energy resources without adding new generation capacity (Haider et al., 2016). Today, demand response can be applied also to the residential sector. Here, the presence of highly connected home appliances, i.e., IoTs will enable a performing communication that is fundamental for controlling and optimizing the energy system in a holistic and proactive fashion. To this aim, aggregators technology is a key element in the communication between operators and end-users (Figure 5). These enable two-way communication to achieve peak-shaving by modifying end-users consumption patterns (Gkatzikis et al., 2013), thus optimizing energy consumption from one hand, and, energy production on the other. In (Good et al., 2017), the authors provided a review of the energy management systems aggregators highlighting the principal gaps at technological, privacy and regulatory level. Precisely, from this review study, it emerges the need for a highly efficient ICT infrastructure, which must be associated with IoT, in order to properly interact with end-users, for managing and balancing the energy production and demand. Since these systems should have access to a broad set of information to let the system work at its best, the authors underlined the need to pay special attention to privacy issues. In fact, high resolution metering data, e.g., home appliances energy consumption, represent a potential risk for privacy violation due to indirect and implicit information carried, which could be easily triangulated by third parties. Finally, the authors identified the need for an adequate regulatory framework for demand response systems, playing a fundamental role in the 


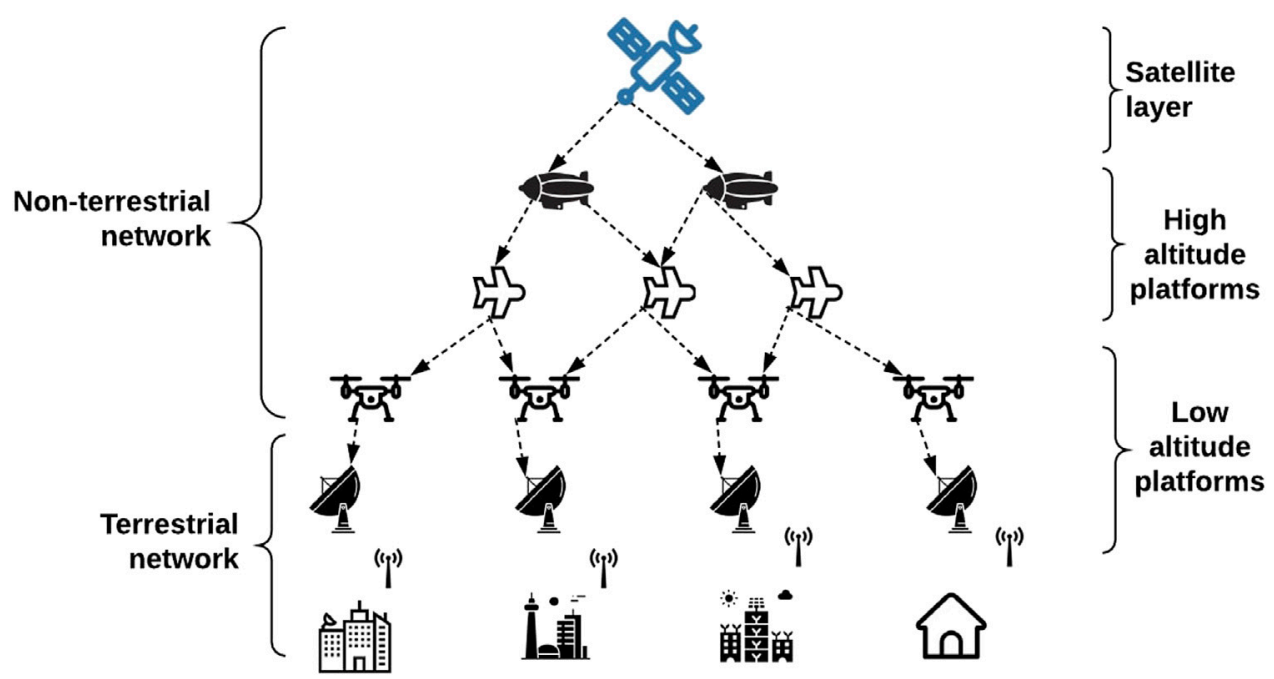

FIGURE 4 | An architecture airborne communication network (Cao et al., 2018).

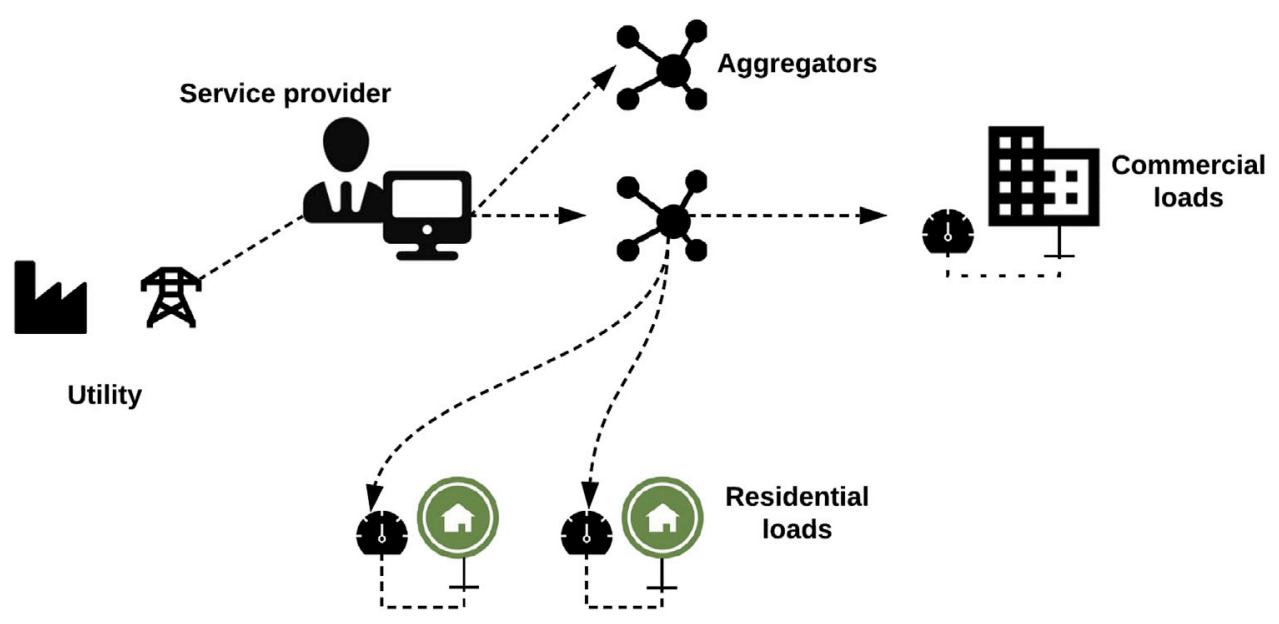

FIGURE 5 | A sample of demand-response application scheme (Elma and Selamoğullari, 2017).

energy market and energy balancing. If these aspects are considered and properly addressed, possibly through strategic cooperation between industries, policymakers, research institutions, demand-side management systems, and aggregators are likely to be the strategic dowel in the smart grid puzzle to achieve a flexible and efficient interconnected energy infrastructure.

\subsection{Cloud Computing}

Cloud computing provides large-scale integrated processing capabilities which are more economically sustainable O'Connor and Appzero (2014). Fang et al. (2016), discussed the role of cloud computing within the smart grid framework, identifying this technology as a potentially beneficial for power system optimization, mitigate disasters, increasing resilience to large-scale failure. If this last aspect is true from one side, from the other side, data centers have to deal with different categories of risks ranging from regulatory, technological, political to climate/ natural. Precisely, electricity blackouts, tornado/hurricanes, fires, flooding, earthquakes or, unexpected events (Ross, 2020). For this purpose, data center operators employ different strategies for business continuity and disaster recovery. These are mainly based on redundancy, i.e., data are stored in different locations and, from a business organizational level, an integrated approach to manage problems is employed to enable business resilience from attacks or natural disasters. There is another problem to deal with, and, in fact, data center providers need to take precautions to prevent damages resulting from mid-size solar flares. This involves the use of transient voltage surge suppression, uninterruptible power supplies, on-site emergency standby 
generators (Jason Verge, 2013). Finally, to mitigate system outages by increasing network resilience, the so-called 'fog computing' can be a strategic paradigm. Fog computing, compared to cloud computing, favorites end-users proximity and it has a wider geographical distribution (Bonomi et al., 2012). In fact, in contraposition with the cloud computing, where data are stored in a remote physical center, fog computing foresees the use of more proxime devices, usually called edge devices, to enable data storage and digital services. From the energy point of view, the cooling energy consumption can reach up to $45 \%$ of the total consumption of data centers in the case of inefficient cooling systems. As the increase in data processing requires increasingly power, innovative cooling solutions are emerging such as Direct-to-Chip or Liquid Immersive Cooling where servers and storage are fully immersed in dielectric fluid (Campbell, 2017). On the other hand, the replacement of personal computers by lightweight computers built to connect to a server from a remote location, could sensibly reduce the electricity consumption by more than $50 \%$ (Gloge et al., 2008). Lightweight computers are significantly smaller than PCs and they do not include fans for dissipation or hard disk, as the whole data processing takes place on the central servers.

\subsection{Communication Protocols}

Communication protocols refer to the set of rules that enable different entities of a communication system to share information through variations of physical quantities. The protocol comprises of the rules, syntax, semantics and, synchronization of the communication (Myers, 2001). Usman and Shami (2013) discussed some of the major communication protocols such as ZigBee and WiMAX, with a specific focus on their application in smart grids and, as stated by the authors, "smart devices have started to reach the consumer market but the interoperability and complete solution for smart grid environment is still far away". In Table 1, an overview of the main communication protocols is presented along with technical characteristics.

\subsection{Prosumers}

Prosumer refers to a player which is involved in the production and utilization of a generic good and it can be translated in "production by consumers". Concerning the energy framework, Parag and Sovacool (2016) watch at the prosumers paradigms identifying three different categories: a peer-to-peer model where agents are interconnected, prosumers-to-grid and prosumers community groups. The authors outlined a possible successful scenario for prosumers' integration in the energy market which could improve residential and commercial energy efficiency, democratize demand-response and prepare society for distributed clean energy technologies. However, the great market design is needed at different levels otherwise, it could easily undermine grid reliability, erode sensitive protections on privacy and inflate expectations to the degree that the prosumer revolution satisfies nobody (Parag and Sovacool, 2016).

\subsection{Artificial Intelligence}

Artificial intelligence and machine learning are increasingly seen as key technologies for building more decentralized and resilient energy grids. These techniques are powerful tools for design, simulation, control, estimation, fault diagnostics, and faulttolerant control in the smart grid (Bose, 2017). However, their development needs to be properly addressed. Some researchers emphasize the need to consider the ethical and social implications of these developments (Robu et al., 2019), and thus, artificial intelligence framework should pass through a regulatory process to enable sustainable development, otherwise, it could result in gaps in transparency, safety, and ethical standards (Vinuesa et al., 2020). But, from a technological perspective, as reported in (Strukov et al., 2019), artificial intelligence has made such huge steps forward that we have arrived at a scientific Frontier where - citing the authors - 'artificial intelligence needs new hardware, not just new algorithm.' This brought some scientists to focus on the possibility of building brain-inspired computing (Strukov et al., 2019). Precisely, the idea of the so-called neuromorphic computing is to design computer chips inspired to the brain, thus merging memory and processing units, achieving impressive computational power and speed with very little power consumption. This will enable complex deep learning networks functioning that would help to solve-in a prompt fashion-complex problems related to the smart grid control.

\subsection{Big Data and Quantum Computing}

Smart sensors networks are a great opportunity for smart grid applications due to the high level of magnitude of data gathering. However, it also brings new challenges and costs for storing and processing consistent flows of information with a high frequency (Jaradat et al., 2015), which are commonly identified with the term 'big data.' Precisely, as report in (Bibri and Krogstie, 2017a), 'big data' universe involves the use of tools (e.g., classification, clustering, and regression algorithms), techniques (e.g., data mining, machine learning, and statistical analysis), and technologies (e.g., Hadoop, Hbase, and MongoDB) that are used to extract useful knowledge from large fluxes of data. In (Tu et al., 2017), the authors reviewed the big data issues for the smart grid framework, highlighting challenges and opportunities. At 2017, the authors believes that the big data domain, even thought it is rapidly leaving, still is in a early stage and, in a future perspective, different technological points should be faced. And these are:

- multi-source data integration and storage,

- real-time data processing, data compression,

- big data visualization,

- and data privacy and security.

For big data analysis, quantum computing may play a fundamental role. In fact (Feynman, 1999) observed that quantum-mechanical systems have an information-processing capability much greater than that of corresponding classical systems, and could thus potentially be used to implement a new type of powerful computer' (Jones et al., 1998). Here, differently from a classical computer that encodes data into fundamental units called 'bits' whose state can be 1 or 0 , a quantum computer encodes data into 'qubits' whose state can be 1,0 or a combination. This is practically translated in a 
TABLE 1 | Communication protocols (Hafeez et al., 2014).

\begin{tabular}{|c|c|c|c|c|c|c|c|}
\hline Feature & $\begin{array}{l}\text { ZigBee/ } \\
\text { IEEE }\end{array}$ & $\begin{array}{l}\text { Bluetooth/ } \\
\text { IEEE }\end{array}$ & Wi-Fi/IEEE & RFID & $12 \mathrm{C}$ & SPI & $\begin{array}{l}\text { HomePlug } \\
1.0 \text { (PLC) }\end{array}$ \\
\hline $\begin{array}{l}\text { Base data } \\
\text { rate }\end{array}$ & $250 \mathrm{kbps}$ & $1 \mathrm{Mbps}$ & $\begin{array}{l}11,000+ \\
\text { kbps }\end{array}$ & - & 100 kbps-3.4 Mbps & $20 \mathrm{Mbps}$ & $14 \mathrm{Mbps}$ \\
\hline Frequency & $2.45 \mathrm{GHz}$ & $2.45 \mathrm{GHz}$ & $2.45 \mathrm{GHz}$ & $120 \mathrm{kHz}-10 \mathrm{GHz}$ & $\begin{array}{l}\lim . \text { To } 100 \mathrm{kHz}, 400 \mathrm{kHz} \text { or } \\
\text { 3.4 MHz }\end{array}$ & $\begin{array}{l}\text { Free ( } \mathrm{n} \mathrm{MHz} \text { to } 10 \mathrm{n} \mathrm{MHz):} \mathrm{Where} \\
\mathrm{n} \text { is an integer from } 1 \text { to } 9\end{array}$ & $5,000 \mathrm{kHz}-1 \mathrm{MHz}$ \\
\hline Range & $10-100 \mathrm{~m}$ & $10 \mathrm{~m}$ & $1-100 \mathrm{~m}$ & $10 \mathrm{~cm}-200 \mathrm{~m}$ & Few meters & $100 \mathrm{~m}$ & $1-3 \mathrm{~km}$ \\
\hline Latency & $30 \mathrm{msec}$ & $18-21 \mathrm{msec}$ & 0.3 usec & 25-300 usec & $\begin{array}{l}\text { Depends on the master } \\
\text { clock }\end{array}$ & Depends on the masted clock & $x$ \\
\hline $\begin{array}{l}\text { Nodes/ } \\
\text { Masters }\end{array}$ & 65,540 & 7 & 32 & - & 1,024 & $2-3$ & $x$ \\
\hline Battery life & Years & Days & Hours & Battery-less & Low power requirement & Low power requirement & Low \\
\hline Complexity & Simple & Complex & $\begin{array}{l}\text { Very } \\
\text { complex }\end{array}$ & Simple & Simple hardware & Simple hardware & Simple \\
\hline Security & 128 bit & 128 bit & $\begin{array}{l}\text { WPA } \\
\text { WPA2 }\end{array}$ & AES 128-bit & $x$ & $x$ & $x$ \\
\hline
\end{tabular}

dramatic improvement of the computational power (Ladd et al., 2010), thus, the possibility to solve extra-large computational and big data challenges in a timely fashion, becomes realistic. In fact, concerning the smart grid context, some proofs-of-concept have been already provided to solve simplified problems, ranging from traffic flow optimization to route optimization for multimodal transport systems (D-Wave, The Quantum Computing Company, 2020). Furthermore, quantum computing is truly a game-changing technology since, as previously stated, it will also likely push the boundaries of cyber security and cryptography. Finally, in a smart grid perspective, quantum computing will enable new paradigms in the energy market by effectively preserving users' privacy and their economic transactions.

\subsection{Complementary Applications, Sectorial Integration and Synergies, Technology Frontiers}

In addition to the abovementioned technologies, there is plenty of further innovative energy applications, management strategies and emerging solutions that, in some form and in some way, will characterize the portrait of the smart grid of the future. For example, without the aim of exhaustiveness, vehicles-to-grid (V2G) and battery swapping applications (Kempton and Tomić, 2005) are complementary paradigms that will take part in the smart grid shaping process for some contexts. Similarly, 5 th generation $\mathrm{CO}_{2}$ district heating network and power-to-gas applications (Götz et al., 2016) are another challange that scientists are currently dealing with. Also, energy storage, in a broader sense of the term, and sectorial integration i.e., industrial symbiosis, waste heat recovery, is to increase the flexibility and sustainability of energy systems operations, affecting decisively, the evolution of our technological landscape for the energy context. Finally, some minor applications such as energy recovery from natural gas distribution (Cascio et al., 2018b) and emerging control strategies such as gas-bagging (Cascio et al., 2018a) applications, in a long term perspective are likely to contribute to shaping the smart grid scenario as well. Or, for the sake of ontological coherency, the smart grid scenario, intended as a whole, is likely to shape the contribution of these applications. Besides, the smart grid of the future will be likely characterized by frontier technologies that are currently being studied or developed. For instance, researchers are developing a technology to convert a wall into a trackpad and motion sensor and this could be achieved thanks to a conductive paint (Patel, 2018). Once this technology will reach a certain level of matureness, smart walls will be presumably able to track people's gestures or monitor appliances. As regards this aspect, it comes intuitively to understand the potential level of insights that could be achieved by monitoring people's body language, gestures and so on. Further aspects affecting the smart grid of the future could reside in complementary sectors and their technological advances. For instance, the space exploration and colonization sector have synergies with the smart grid sector. In fact, "NASA and smart grid both need autonomous controls" (Soeder, 2015). A further practical example of intersectoral synergy can be represented by the SpaceX Starlink project. This consists of a constellation of thousands of mass-produced small satellites working in combination with ground transceivers, to provide broad internet access, thus improving smart grid applications performance, making it easy to implement smart grid technologies also in remote areas.

\section{REGULATION, SECURITY AND SOCIAL FACTORS}

In this section, the smart grid domain will be analyzed from a broader perspective, considering transdisciplinary issues, such as social-related considerations, and technical/engineering challenges as well.

\subsection{Regulation, Privacy and Cyber Security}

According to Iqtiyanillham et al. (2017), the European Union maintains world leadership in smart grid technology. The authors identify the integration of various disciplines, overcoming regulatory barriers, technology maturity, and consumer engagement as the key challenges for those experts involved in 
disciplines gravitating around the smart grid. This is valid especially for international operators such as the European Network of Transmission System Operators for Electricity (ENTSO-E) and the Coordination of Electricity System Operators (CORESO) which are the agencies that presently coordinate system interconnection and operation (Iqtiyanillham et al., 2017). The orchestration of the interdisciplinary problem has been recently faced by the European Commission by instituting a Smart Grid Task Force which comprises different subgroups. For instance, one group is focusing on cyber security and it is to prepare the ground for sector-specific rules for cyber security aspects of cross-border electricity flows, on common minimum requirements, planning, monitoring, reporting, and crisis management for the electricity subsector (European Smart Grids Task Force, 2019b). Other groups, instead, focuses on the deployment of demand-side flexibility and the specific case of explicit demand response in Europe (European Smart Grids Task Force, 2019a).

The European Commission, in 2019, adopted specific guidance (recommendation C(2019)240 final and SWD (2019) 1,240 final) to implement cyber security rules with the final aim to improve awareness and organization in the energy sector (European Commission, 2020). However, historically, technology and regulations travel at different speeds and, concerning the digital e-cosmo, technologies here are often put on the market without proper comprehension of the privacy and cyber security risks. As highlighted in (Mylrea, 2017), the technologies involved in the smart-grid landscape, will have to understand how the information is collected, stored, sold, used, and what jurisdictions does the information traverse. This challenge it's far from being trivial since, as clearly explained by Anderson (2019), it is necessary to identify security measures for privacy protection which have to involve both data and metadata linked to users energy usage and other domains. Precisely, regulations will have to be designed and implemented with a resolutive approach, facing in a clear, explicit and non-ambiguous way the jurisprudentia relative to privacy violations due to business intelligence triangulations based on metadata-type-information. Besides, the "flip side" of the digital innovation does not only involve privacy. In fact, in the smart grid framework, Khatoun and Zeadally (2017) identify privacy and public safety as a priority for political debate and scientific research, highlighting the imperative need to contrast cyber crime in smart cities for every class of cyber-attack: cyber warfare, terrorism, industrial espionage, activism, economic reasons to jokes Otuoze et al. (2018).

\subsection{Behavioral Aspects and People's Perception}

As reported in (Bigerna et al., 2015), multidisciplinary cooperation is needed to develop scientific research on smart grids since the creation of new infrastructures is generally linked to acceptance problems which are important for the adoption of new technologies. For instance, social acceptance is an important aspect that may determine the smart grid evolution. This aspect has been demonstrated by (Bugden and Stedman, 2021) where social acceptance of the smart grid decreases over time, challenging optimistic views on how user engagement with energy supply and demand can transform our energy systems. The inclusion of conscious consumers in the process is a fundamental issue to be addressed in the smart grid realization where the problem involved is extremely complex due to its multidisciplinary nature. In fact, there is plenty of social and psychological issues gravitating around the innovation management of the smart grid domain. These range from human factors and energy consumption to effect of technology on society, also in a broader sense of the term, thus involving issues at the anthropological level as well. In this perspective, computational social sciences may be an fundamental tool to address the degree of complexity of the emerging challenges and the innovation management, in fact, "the computational sciences cover the use of simulations, data mining, behavioral tracking, or large-scale field experiments". (Nambisan et al., 2017). Energy consumption in buildings - especially residential - largely depends on human behavior and the context in which energyrelevant decisions are being made, thus social sciences and IT could benefit from each other (Tiefenbeck, 2017). In this regard, De Dominicis et al. (2019) analyzed the impact of real-time feedback on residential electricity consumption, highlighting how feedbacks based on social comparison resulted in a sensible long-term reduction. Tiefenbeck et al. (2019) proposed a case study based on 6 hotels monitoring - 265 rooms, 19.596 observations - demonstrating how sensible is the behavioral factors in energy consumption. Precisely, this study proved that a real-time feedback intervention would result in a considerable $11.4 \%$ energy reduction. Furthermore, gamification i.e., the use of game mechanics to drive engagement is a reinforcing factor that has been shown to encourage targeted behaviors with instant positive feedback (Bradley et al., 2011).

At a societal level instead, Boudet (2019) reviewed the literature on public perceptions relative to different energy technologies from a broader perspective. The author concludes highlighting how research on public perceptions relative to new energy technologies will have to continue to shed valuable light on the complex interface between energy technologies and the broader society they serve. In fact, as stated by Norman (2018), cities exist within a wider system and it may take more than technological advances, innovation, and city autonomy to develop a sustainable urban future.

\subsection{Robustness and Resilience}

In general, the smart grid is to all effect a set of multi-domain interdependent networks of systems and human players, and this makes the smart grid - whatever is its configuration and level of integration - subjected to those common risks that are typically manifested in all complex networks: cascade failures. Failures have been studied especially in the electrical transmission domain and, overload failures usually propagate through collective interactions among system components and the propagation dynamics of the cascading failures are essentially unknown (Daqing et al., 2014). Buldyrev et al. (2010) developed a framework for understanding the robustness of interacting networks subject to such cascading failures. From the findings of this study, it emerges the need to 
consider interdependent network properties in designing robust networks. In fact, according to the authors, a broader degree distribution increases the vulnerability of interdependent networks to random failure, which is opposite to how a single network behaves. The same needs at the systems' design level, has been highlighted in (Vespignani, 2010). For the electrical transportation infrastructure, some efforts have been made to prevent power outages. For example, there is a technology called synchrophasors which are equipped with GPS, this technology gives you microsecond accuracy of time across the whole power system (Haq et al., 2017). Transient dynamic behaviors for dynamically induced cascade failures have been studied by Schäfer et al. (2018), highlighting the need for further investigation to outline failures propagation dynamics and mitigation strategies. Robu et al. (2019), wisely highlighted the fundamental ethical and social challenges for the digital revolution which is irreversibly shaping the smart grid scenario. Conclusions suggest the need for a careful control for the design and realization of the smart grids, whose increasing architectural complexity and AI need to be properly ensured, to prevent, for instance, drastic blackouts. Thus, except for the presumed reduction of the pollution level (Ball, 2004), blackouts might be responsible for generating several dramatic issues and its prevention is an unquestionable priority. Among all the possible causes, blackouts may be originated also by solar flares. Solar flares produce high energy particles (primarily high-energy protons) and radiation (primarily x-rays). To be more precise, this last disturb the ionosphere - from 9 to $200 \mathrm{~km} \mathrm{-} \mathrm{affecting} \mathrm{radio}$ communications. Besides, along with energetic ultraviolet radiation, they heat the Earth's outer atmosphere, causing it to expand. This increases the drag on Earth-orbiting satellites, reducing their lifetime in orbit (National Aeronautics and Space Administration - Goddard Space Flight Center, 2020) or damaging astronauts in orbit (Burch, 2004), or cause severe damage to electrical systems and communications (Moriña et al., 2019). Thus, both intense radio emissions from flares and changes in the atmosphere can degrade satellite communications, especially for Global Positioning System (GPS) measurements (National Aeronautics and Space Administration - Goddard Space Flight Center, 2020). Along with solar flares, scientists now understood that the major geomagnetic storms are induced by coronal mass ejections and this are frequently associated with flares. Coronal mass ejections likely have a 11-years cycle. There is a serious problem associated with geomagnetic storms that is the damage of Earth-orbiting satellites, especially those in high, geosynchronous orbits. As reported in (National Aeronautics and Space Administration - Goddard Space Flight Center, 2020), in 1989 high currents in magnetosphere induced high currents in power lines, blowing out electric transformers and power stations and, this risk involves mainly high altitude zones, where induced currents are greatest, and those areas having long power lines and/or where ground is poorly conducting (National Aeronautics and Space Administration - Goddard Space Flight Center, 2020). Due to this risk, scientists are exploring the possibility to predict Carrington events. In this perspective, some authors estimated that the probability of occurrence of an 1859-Carrington-like event is estimated to be between 0.46 and $1.88 \%$ - much lower than what is identified in the literature. While, on the other hand, some scientists are even proposing to protect Earth from solar flares (Lingam and Loeb, 2017) by employing a magnetic field to deflect charged particles. The authors approached the feasibility of the measure from a physical perspective, in terms of its basic physical parameters, highlighting no specific limitations. This research carry-out a heuristic analysis of the potential economic impact of such an extreme space weather event, comparing the cost of the mission for lifting a $10^{5}$ tons object into space, would be around $\$ 100$ billion-assuming a $\$ 1,000$ per $\mathrm{kg}$ - which is comparable to the total cost of the International Space Station, but still 3-4 orders of magnitude lower than the economic loss generated by a catastrophic event (Lingam and Loeb, 2017), that would directly compromise the smart grid.

\section{HOW SMART IS THE GRID}

In this section, based on the smart grid anthology presented, an idealization of the smart grid concept is carried out in order to support, firstly, the definition of a taxonomic framework for smart grid assessment, secondly, a discussion relative to the ontology of the smart grid and its transition (Figure 6), thus to focalise the premises behind the realization of the smart grid concept.

\subsection{Subjects and Objects}

To focalize the level of complexity that will likely characterize the current and the emerging smart grid, it would be helpful to make few steps backward, trying to identify from a distant perspective, which are the main elements, interconnections, layers, and actors that will come into play, defining the presumable final portrait of the whole set. To this aim, in Figure 7, a simplified scheme of an idealized smart grid is presented. Here, the smart grid subborders can be ideally divided into resources, supply, storage, and harvesting. Concerning the energy vectors, electricity, natural gas, thermal energy, hydrogen networks, other renewable carriers and eventually non-renewable carriers e.g., oil. Finally, Figure 7 includes the ICT overall infrastructure and enabled paradigms (cloud and fog computing and demand-side management etc). These are linked to a complementary layer which ideally involves issues concerning the economic, financial and regulation dynamics, along with social one.

\subsection{Synergies vs. Complexity}

The main issue emerging from Figure $\mathbf{8}$ depicting the idealized smart grid universe, concerns the dichotomy 'synergy vs complexity' which derives from the multisectoral integration that digitalization and technological progress has made enabled. In fact, on the one hand, the sectorial integration makes it possible to give rise to synergies that would most likely be translated in energy, economic and environmental benefits, which have been thoroughly discussed above. On the other hand, instead, digitalization is constantly increasing the level complexity of the grid enabling a high level of sectorial interdependency. Thus, without the aim of exhaustiveness, we can state that, depending on the system architecture, energy service continuity and performance in the next future might 


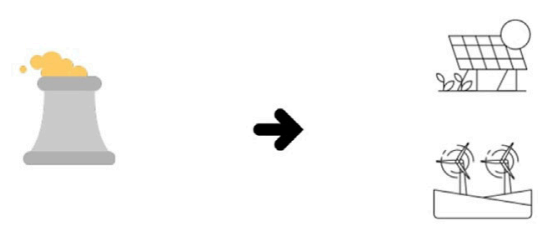

1 Plant, 1 GWhe

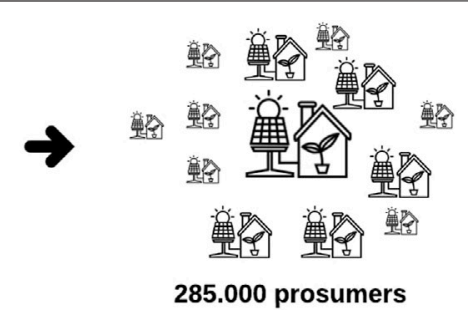

285.000 prosumers

FIGURE 6 | Paradigm shift: from centralized to distributed generation.

intimately be linked to information deriving from IoTs environments, which is in turn subjected to ICT infrastructure functioning and/or GPS services, which in turn are dependent to satellites integrity. At this stage, the main concern outlined from this study involves our lack of comprehension and ability to predict the level of resilience of the emerging smart grids that, moreover, varies from case to case. In this sense, the possibility that system integration and sophisticated technological solutions might not be the best compromise for large-scale systems, should be taken into account. In fact, system complexity foreseen being subjected to a higher number of risks or, in other words, citing Ford, "what is not there, does not break". To be more precise, considering how the smart grid tends to be designed so far, it should not be excluded the possibility that an extreme event, such as Carrington event, or a set of non-predictable circumstances as the dramatic Fukushima disaster teach us - could generate a sequence of large-scale failures which could likely evolve on the mid-term, compromising communication, energy services continuity, and reflecting on the society by perturbating, in a non-desirable way, economic equilibriums and social dynamics.

\subsection{Taxonomy and Categorization}

Starting from the smart grid anthology carried out in the previous sections, a preliminary taxonomic framework for smart grid categorization can be proposed. This framework is conceptually based on the analysis of the technological evolution developed through three different progressive generations of the technological maturity and the properties of a grid (Figure 8). First-generation grids can be characterized by less sophisticated and less advanced technological content and is mainly targeting centralised production systems based on transmission lines: e.g., electric transmission infrastructure equipped with ICT for power quality monitoring and control. Second generation grids is considering more decentralised production and consumption, they are characterized by a lowest common denominator which is represented by a distributed-based generation. Finally, third generation grids would embed the characteristics of the previous ones while they are considered to be the most sophisticated as they would foresee the use of "pseudo-empathic" features where, for example, users engagement is enabled through AI-based tailored feedback and effective dynamically regulated end-users communication. Also, it is worth highlighting how the term 'smart grid' assume a broader meaning, and it tends to merge with the 'smart city' or definitions, as in the reality the domain's borders be intimately integrated with complementary domains. In Figure 8, a systematic decomposition is applied to outline a smart grid framework based on the above mentioned three generations (1st, 2nd, and 3rd), while each generation is identified by a generic taxonomy. These are following discussed in details.

\subsubsection{First Generation}

- Integrated The simplest possible instance of an integrated energy system can be represented by a transmission network equipped with ICT technologies for monitoring and power quality control. However, in the reality, the integration concept might assume a broader meaning, thus involving other energy carriers, including water, gas and thermal networks, from the production side, embracing residential and tertiary sectors through IoTs technologies, for the end-users side. As discussed in the previous section, energy system integration is the key to achieve higher operational flexibility thus to theoretically unlock the systems' potential at a large scale, in terms of operational optimization and renewable resources penetration. When integration occurs at a wider level, it can involve also transportation sector or industry e.g., vehicles to grid application or industrial symbiosis. However, system integration is not always synonymous of optimized operations, as it should be intended as a necessary but not sufficient condition to achieve a higher level of sustainability.

- Optimized Energy systems optimization involves the conjunct resolution of rigorous and complex mathematical problems across three different levels: system configuration (synthesis problem), design (component size) and operation (system control). These levels are not "watertight compartments" as, for instance, optimal design could be related to control and vice-versa. Similarly, even if the optimization is conducted through rigorous mathematical models, it remains a relative concepts whose result can varies depending on the dimension of the conceptual borders and study premises: building level, district level, regional or national level. Of course, in this perspective, to be characterized as "optimized" the energy systems architecture, design and control, should be desirably optimized in a long-term perspective, thus involving also aspects such as climate change resilience and anthropological viability for a sustainable inheriting for future generations. 


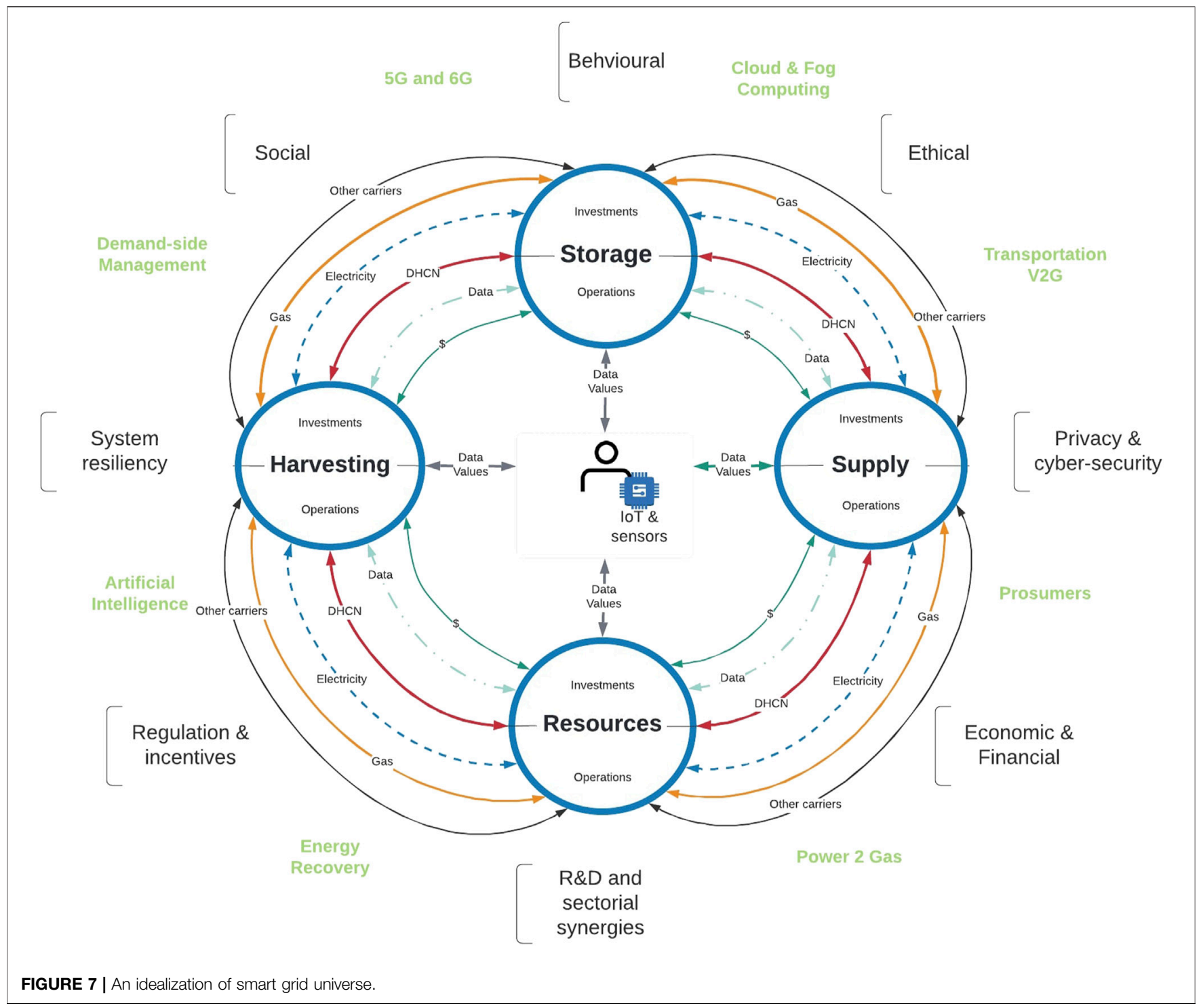

- Secure As discussed in the previous sections, information and communication technologies are revolutionizing the energy landscape, enabling new positive paradigms and business models. However, ICT brings new challenges for privacy and cyber-security which are destined to call the society to develop novel frameworks and technologies that concretely allow us to create a "secure" energy system. From a privacy perspective, it would be necessary, for a secure energy system to employ high data and metadata protection standards, being at the same time resilient to cyber-attacks. But, "security" goes farther than the ICT domain, as it also involves the concept of system resilience and homeostatic features to environment changes and to drastic, unexpected, and extreme scenarios. For instance, and without the aim of completeness, these might include resilience to pandemics, tornado, earthquakes, terrorism, etc, foreseeing also extreme space weather events, high altitude orbits monitoring and space crime security. As regard to these last points, energy system design policies should be harmonized with respect to space programs and, last but not least, telecommunication technologies, with specific reference to $5 \mathrm{G}$ and $6 \mathrm{G}$ should be thoroughly investigated from a health perspective before being deployed.

\subsubsection{Second Generation}

- Distributed Renewable penetration, energy technology accessibility, and ICT revolution are some of those main factors that are shaping the energy conversion and management paradigm, letting it switch from centralized to distributed generation. Decentralization is likely going to positively affect different domains ranging from market dynamics, energy accessibility, to energy system resilience. Especially on this last point, a heterogeneous and context-harmonized energy system is desirable, thus 


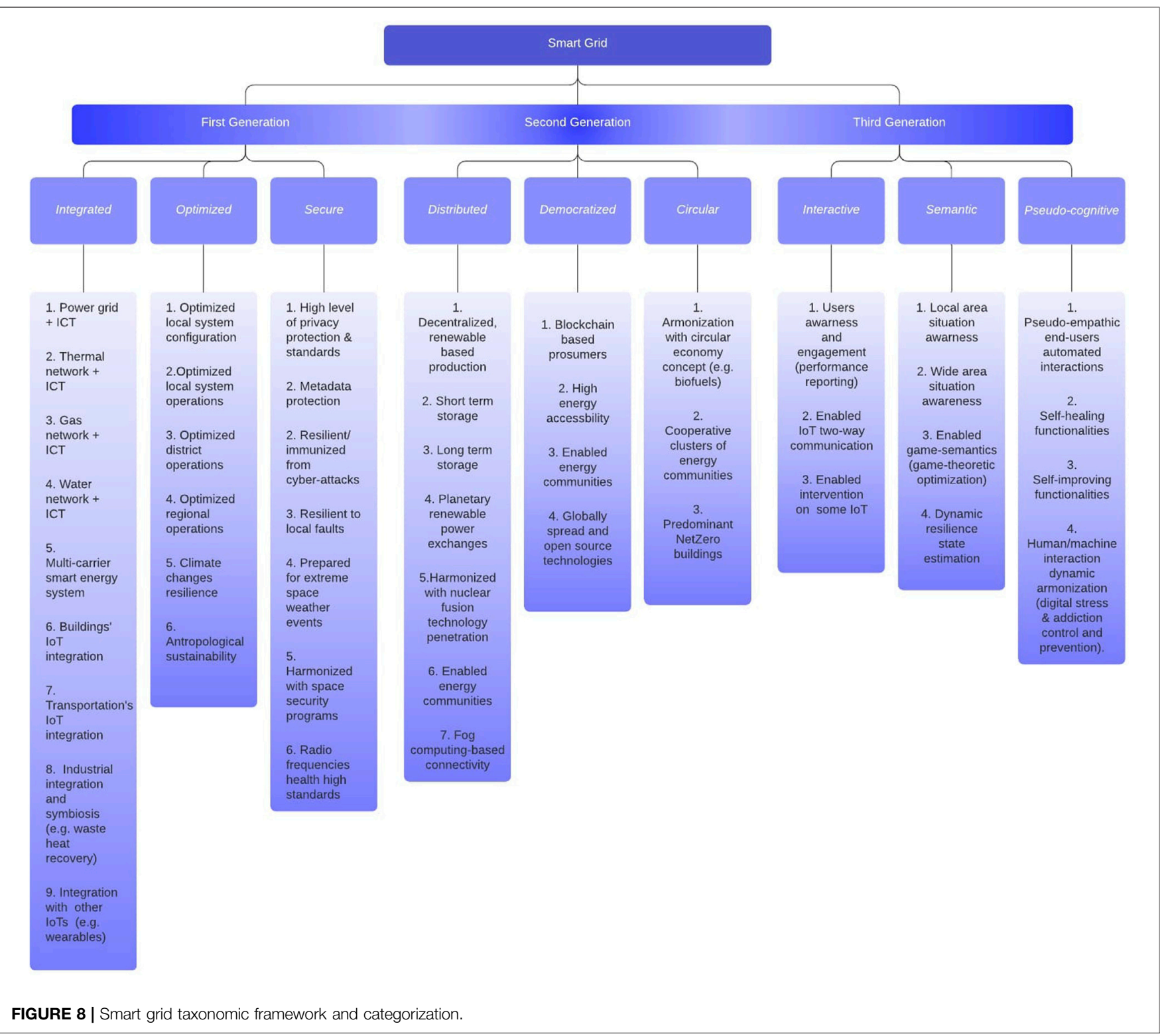

technological diversity should be encouraged also for the ICT domain, promoting fog-based computing for instance. The level of decentralization of electrical systems could also evolve in planetary grids, where renewable production is capitalized through power exchanges between different time zones (e.g., Europe, United States-China) Monti et al. (2018). Finally, the design or retrofitting of a generic energy system should be done by favoring the decentralization but also considering the potential penetration of nuclear fusion. Nuclear fusion might be available for industrialized countries by the mid of this century (ENEA, 2020) and, how it will affect the renewable market and renewable technology penetration? Will we assist to a re-centralization of the energy production with nuclear fusion? With this in mind, energy system should be designed and developed on a long term perspective, trying to find a harmonized coexistence of technologies, to keep the objective benefits (commercial, resilience etc) that the decentralization paradigm brings by its nature.

- Democratized Decentralization is the antechamber of the ambitious challenges of what is called energy democratization. A distributed energy system with a widespread renewable generation "prepares the terrain" for enabling those paradigms which are likely to unlock energy accessibility at a global scale, with an undoubtedly positive impact on geopolitical equilibrium, smoothing/ neutralizing resource monopolization. As discussed in the previous section, one of the most important technologies for creating a "democratized" energy system is certainly the blockchain which will be capable to unlock, for instance, a reliable market framework for peer-to-peer energy exchange across energy communities and prosumer clusters. 
- Circular. Circularity refers to the virtuous organization of a economic system, included an energy system, based on the reuse, sharing, repair, refurbishment, re-manufacturing and recycling to create a closed-loop system, minimising the use of resource inputs and the creation of waste, pollution and carbon emissions (Geissdoerfer et al., 2017). Examples of virtuous energy systems could be represented by bio-fuels production and local exploitation, or netZero energy buildings as, for instance, the Australian Sustainable Buildings Research Centre (University of Wollongong, 2020)

\subsubsection{Third Generation}

- Interactive This taxonomy refers to the case where end-users are pro-actively engaged in the energy management process, thus, achieving a certain level of awareness through system interactions enabled by ICT and IoT technologies. In this case, a two-way communication and the possibility for the system to control the operational status of some IoTs from the demand side, becomes a fundamental prerequisite.

- Semantic Semantic functionalities are possible when the energy systems are enough mature and sophisticated to enable real-time wide-area optimization (wide-area awareness), thus, involving energy exchanges between clusters of prosumers with fair gametheoretic based control. Also, the dynamic resilience of the energy system is eventually assessed to ensure service continuity across the communities.

- Pseudo-cognitive When digital technologies and artificial intelligence are strategically employed in energy systems management, advanced functionalities might be enabled, and these refers to self-healing, pseudo-emphatic end-users communication, and even e-stress monitoring and control. This refers to the possibility to generates customized and tailored automation based on users' habits, harmonizing the user engagement with respect to energy efficiency and psychological aspects as well, thus avoiding stress generated by excessive use and presence of digital technologies in the human environment.

Finally, it is important to highlight that the technological development process is heuristics and iterative by its nature rather than linear. And this means that, when applying this framework to the reality of today's technological smart grid scenario, third generation's features might be found in first or second generation grids for instance. On the other hand, it is true that this would make the categorization of a grid a challenging task and every labeling attempt might result to be not consistent after all. However, when this framework is employed in conjunction with a structured road map of propaedeutic actions designed for the specific context, classification uncertainty might be neutralized as, for example, achieving third-generation status might require the accomplishment and the integration of features of the previous generations (second and first). Finally, the level of smartness of a generic grid, even if objective criteria are employed, tends to result to be a more relative concept rather than objective, as there might be different possible compromises of first and third generation features for instance, that would result in an harmonized solution with respect to the local context and the territory priorities. In other words, for example, a first generation grid is characterized by a set of advantages (simplicity, resilience etc) that might represent the smartest solution for that given context. Concluding, even it might result apparently paradoxical, it might be also true that first generation grids might not be synonymous of a less sustainable solution. Concluding, a fundamental aspect that should be taken into account when assessing the sustainability of a grid, is the amount of auxiliary energy (i.e., the eventual $\mathrm{CO}_{2}$ production) necessary for the conduction and operation of the grid itself (including ICT and IoTs related energy consumption) i.e., directly or indirectly associable to the presence of the energy system itself. In this perspective, it should be noted that it IoTs technologies is being widespreadly used (smart city, agriculture, transportation, etc.) These devices will produce an important amount of e-waste while consuming an important amount of energy as well (Abedin et al., 2015), thus eventually generating carbon emissions.

\section{DISCUSSION: NEXT STEP?}

Two levels of actions are identified as 'next step' to increase the chances of achieving a sustainable grid in the most general sense of the term. These are mid-terms actions and long-term actions. Concerning the mid-term, there are several issues that researchers, industries and regulators should focus on, and these are:

- Ontological Study and debate of the ontological premises relative to the realization of the smart grid concept and its contours. Precisely, apart from the potential RETs share increase that digital technologies could enable, from a social, environmental and human-life-quality perspective, where the progress resides when creating a highly digitalized and interdependent grid? From this point, there are several subissues-following presented-that need to be properly and thoroughly discussed, avoiding leaving them to be pulled and shaped by market and commercial speculation.

- Sociological Social acceptance problems are important for the adoption of new technologies. Computational social sciences and transdisciplinary researches need to investigate the emerging complex relation between sociecty and technology, in order to avoid excessive optimistic views on how users' engagement can transform our energy system. Also, cyber technologies offer new risks for new types of addiction (Takahashi, 2018). Thus, it is important to understand social and psychological eventual risks deriving from a highly digitalized environment and surrounding (IoT) which, as previously described, are likely to be functional to the presence of a fully automated grid. This refers especially to people's homes.

- Ethical 'Permanent records' (Anderson, 2019) and sensible data storage risk to subtly erode our freedom-in the most general sense of the term-at its roots. In particular, for instance, the fact 
is that we have no idea about the final effect on individuals' physiology generated by the conscious awareness of the presence of 'permanent records' or all those information gathers by digital technologies, including social media. Thus, to the best of our knowledge, we cannot exclude the possibility that these may be a serious ontological bug in our society which is likely to be ignored by the most due to its subtle and non-measurable effects. In this sense, from a general perspective, the evolution of the smart grid will drastically increase the e-traffic, thus its development must be designed (or retrofitted) by paying particular attention to users' privacy to prevent invisible societal disasters whose eventual existence, is unexplored terrain.

- Technical Studies are desiderable to understand complex dynamics and emergent behaviors of interdependent systems (ICT, energy systems, IoT, and complementary associated sectors e.g., transportation and autonomous vehicles).

- Regulations Normative should be designed to rigorously assess final energy benefits (if any) generated by the employment of different digital measures and paradigms at different levels: urban level e.g., aggregators, building level e.g., electronic 'smart' devices for HVAC control, etc. Thus, the design of new incentives to unlock and regulate new business models such as peer-to-peer energy exchange is very recommendable to sustain energy communities, increase system resilience.

- Research and training Increase the number of strategic research programs to enrich knowledge, and generate highly trained professionals to enable dedicated consultancy to design tailored solutions (through digital twins for instance) to approach the unavoidable architectural heterogeneity of the emerging smart grids.

On the long-term perspective instead, there are further aspects that directly or indirectly linked to the smart grid universe. These range from space-security i.e., space crime prevention e.g., satellites kidnapping, to missions and projects to explore the Sun to increase our comprehension of the star cycles and extreme solar events forecasting, to prevent eventual drastic blackouts, transversal network cascade failures, and vertical inter-sectorial domino effects. Also, it might be necessary to re-think and harmonize the eventual penetration roadmaps of nuclear fusion technologies with respect to the distributed generation concept and the advantages derived from this, thus neutralizing the risk of a 're-centralization' of the energy production that nuclear fusion technology would likely be able to induce due to its game changing potential.

\section{CONCLUSION}

In this article, a general transdisciplinary analysis of the existing and emerging technological solutions for the smart grid was presented. From a technological perspective, different technological solutions have been discussed and contextualized with respect to the smart grid framework, identifying synergies and limitations. The technologies and concept considered are IoTs, smart meters, blockchain, 5G/6G, quantum computing, demand response, cloud and fog computing, communication protocols, prosumers, artificial intelligence, and further complementary applications. From this smart grid anthology, a taxonomic model for smart grid categorization was outlined. This involves three different generations (1st, 2nd, 3rd), while each generation is identified by a generic taxonomy i.e., integrated, optimized, secure (1st) distributed, democratized, circular (2nd) interactive, semantic and pseudocognitive (3rd). Furthermore, from the scenario portrayed, a set of issues involving the regulation, security, and social frameworks have been further derived in a theoretical fashion. From an engineering perspective, the presumed most critical issue outlined involves the dichotomy 'synergy vs complexity,' which derives from the multisectoral integration that digitalization and technological progress has made enabled. Precisely, this refers to our lack of comprehension of faults propagation mechanisms, and thus the level of resilience of the emerging smart grids. For instance, the highest risk deriving from an interdependent highly digitalized grid, might be represented by the possibility of a Carrington event or a set of non-predictable, non-desirable circumstances. Finally, the engineering challenges and the mitigation/neutralization of these risks can be mostly addressed by employing a natureinspired development approach: the human body for instance, is the best definition of a extremely complex but sustainable system, i.e., it is a truly smart system. Thus, the energy systems of our future societies, should - and most likely will - be inspired to the human body intended as a homeostatic system involving energy supplying, managing, storing, harvesting and control, and these features will likely characterize the taxonomy of the fourth generation smart grids. Besides, the technological framework which is developed is also intimately linked to socio-anthropological aspects that are identified, without the aim of completeness, in this review. The most critical aspect outlined through this study resides in the risk of an "ontological misunderstanding" relative to the realization of the smart grid and its contours, which could likely occur during the development path. In fact, at a global level, from a human-life-quality perspective, it's known that the main advantage deriving from grid digitalization is linked to the possibility to increase the flexibility of the system, thus increasing the renewables share and operational optimization. However, on the other side, we should also keep in mind that digital technologies, which are likely to be functional to the presence of a fully automated grid, generate new potential risks, e.g., human-machine relation management (Takahashi, 2018), problems related to individuals privacy due to the growth of data and meta-data gathering, thus enabling a dramatic, un-ethical level of individual insights through business intelligence triangulations.

The misunderstanding of the philosophical premises and the presumable incomprehension of the consequences of the digital tsunami - from every perspective - clearly generated 
by a non-controlled market speculative pull, might tend to consolidate the presence of a technology-based society, increasing the possibilities to realize what could be tagged as 'digital middle-age,' that might consists in an apparently advanced society characterized by contradiction where the presence of vertical technological advances is in contraposition to a compromised individuals wellbeing. To prevent this not-desirable scenario, thus, to enable true societal progress, as previously reported by other scientists (Bigerna et al., 2015), we further underline the imminent need of multidisciplinary cooperation, increasing the humanities and social sciences contribution to properly address the smart grid development, avoiding to let commercial speculation and un-ethical choices to lead and shape our future society.

\section{REFERENCES}

Abedin, S. F., Alam, M. G. R., Haw, R., and Hong, C. S. (2015). “A System Model for Energy Efficient green-iot Network," in 2015 International Conference on Information Networking (ICOIN). IEEE, 177-182.

Alahakoon, D., and Yu, X. (2015). Smart Electricity Meter Data Intelligence for Future Energy Systems: A Survey. IEEE Trans. Ind. Inform. 12, 425-436. doi:10.1109/tii.2015.2414355

Anderson, P. D. (2019). Edward Snowden: Permanent Record. Berlin: Springer.

Andoni, M., Robu, V., Flynn, D., Abram, S., Geach, D., Jenkins, D., et al. (2019). Blockchain Technology in the Energy Sector: A Systematic Review of Challenges and Opportunities. Renew. Sustain. Energ. Rev. 100, 143-174. doi:10.1016/j.rser.2018.10.014

Ball, P. (2004). Blackout Clears the Air. (Accessed March 23, 2020).[Dataset]

Balta-Ozkan, N., Davidson, R., Bicket, M., and Whitmarsh, L. (2013). The Development of Smart Homes Market in the uk. Energy 60, 361-372. doi:10.1016/j.energy.2013.08.004

Bastida, L., Cohen, J. J., Kollmann, A., Moya, A., and Reichl, J. (2019). Exploring the Role of Ict on Household Behavioural Energy Efficiency to Mitigate Global Warming. Renew. Sustain. Energ. Rev. 103, 455-462. doi:10.1016/j.rser.2019.01.004

Bibri, S. E., and Krogstie, J. (2017a). Ict of the New Wave of Computing for Sustainable Urban Forms: Their Big Data and Context-Aware Augmented Typologies and Design Concepts. Sustain. cities Soc. 32, 449-474. doi:10.1016/ j.scs.2017.04.012

Bibri, S. E., and Krogstie, J. (2017b). Smart Sustainable Cities of the Future: An Extensive Interdisciplinary Literature Review. Sustain. cities Soc. 31, 183-212. doi:10.1016/j.scs.2017.02.016

Bigerna, S., Bollino, C. A., and Micheli, S. (2015). "Overview of Socio-Economic Issues for Smart Grids Development," in 2015 International Conference On Smart Cities And Green ICT Systems (SMARTGREENS) (IEEE), 1-6.

Bonomi, F., Milito, R., Zhu, J., and Addepalli, S. (2012). "Fog Computing and its Role in the Internet of Things," in Proceedings of the First Edition of the MCC Workshop on Mobile Cloud Computing, 13-16.

Bose, B. K. (2017). Artificial Intelligence Techniques in Smart Grid and Renewable Energy Systems-Some Example Applications. Proc. IEEE 105, 2262-2273. doi:10.1109/jproc.2017.2756596

Boudet, H. S. (2019). Public Perceptions of and Responses to New Energy Technologies. Nat. Energ. 4, 446-455. doi:10.1038/s41560019-0399-x

Bradley, P., Leach, M., and Torriti, J. (2011). A Review of Current and Future Costs and Benefits of Demand Response for Electricity. Centre for Environmental Strategy Working Paper 10.

Bugden, D., and Stedman, R. (2021). Unfulfilled Promise: Social Acceptance of the Smart Grid. Environ. Res. Lett. 16, 034019. doi:10.1088/1748-9326/abd81c

Buldyrev, S. V., Parshani, R., Paul, G., Stanley, H. E., and Havlin, S. (2010). Catastrophic cascade of Failures in Interdependent Networks. Nature 464, 1025-1028. doi:10.1038/nature08932

\section{AUTHOR CONTRIBUTIONS}

ELC-the main author of this research-worked synergically with LG, ZM, FM to enable a harmonious, fruitful high-level intellectual discussion. All the authors have participated in the development process behind this research paper with effective, high-quality contributions.

\section{FUNDING}

This work has received support from the Swiss Centre for Competence in Energy Research on the Future Swiss Electrical Infrastructure (SCCER-FURIES) with the financial support of the Swiss Innovation Agency (Innosuisse-SCCER program).

Burch, J. L. (2004). The Fury of Solar Storms. (Accessed March 23, 2020).[Dataset] Cali, U. (2019). Demystifying the Energy Blockchain Landscape: Technical, Economic and Legislative Aspects. Available at: https://energycentral.com/c/ um/demystifying-energy-blockchain-landscape-technical-economic-andlegislative (Accessed Jan 14, 2021).[Dataset]

Campbell, S. (2017). Is Liquid Cooling Ready to Go Mainstream?. Available at: https://www.hpcwire.com/2017/02/13/liquid-cooling-ready-go-mainstream/ (Accessed Novemebr 27, 2020.[Dataset]

Cao, X., Yang, P., Alzenad, M., Xi, X., Wu, D., and Yanikomeroglu, H. (2018). Airborne Communication Networks: A Survey. IEEE J. Selected Areas Commun. 36, 1907-1926. doi:10.1109/jsac.2018.2864423

Cascio, E. L., De Schutter, B., and Schenone, C. (2018a). Flexible Energy Harvesting from Natural Gas Distribution Networks through Line-Bagging. Appl. Energ. 229, 253-263. doi:10.1016/j.apenergy.2018.07.105

Cascio, E. L., Von Friesen, M. P., and Schenone, C. (2018b). Optimal Retrofitting of Natural Gas Pressure Reduction Stations for Energy Recovery. Energy 153, 387-399. doi:10.1016/j.energy.2018.04.011

Chawla, Y., and Kowalska-Pyzalska, A. (2019). Public Awareness and Consumer Acceptance of Smart Meters Among Polish Social media Users. Energies 12, 2759. doi:10.3390/en12142759

Daqing, L., Yinan, J., Rui, K., and Havlin, S. (2014). Spatial Correlation Analysis of Cascading Failures: Congestions and Blackouts. Scientific Rep. 4, 1-6. doi:10.1038/srep05381

Data Center Map (2020). Locations. Available at: https://www.datacentermap.com/ (Accessed March 23, 2020).[Dataset]

De Dominicis, S., Sokoloski, R., Jaeger, C. M., and Schultz, P. W. (2019). Making the Smart Meter Social Promotes Long-Term Energy Conservation. Palgrave Commun. 5, 1-8. doi:10.1057/s41599-019-0254-5

Di Ciaula, A. (2018). Towards 5g Communication Systems: Are There Health Implications?. Int. J. Hyg. Environ. Health 221, 367-375. doi:10.1016/ j.ijheh.2018.01.011

Dileep, G. (2020). A Survey on Smart Grid Technologies and Applications. Renew. Energ. 146, 2589-2625. doi:10.1016/j.renene.2019.08.092

D-Wave, The Quantum Computing Company (2020). Applications. (Accessed March 23, 2020).[Dataset]

Edison Tech Center (2013). The History of Electrification: The Birth of Our Power Grid. [Dataset].

Elma, O., and Selamoğullari, U. S. (2017). "An Overview of Demand Response Applications under Smart Grid Concept," in 2017 4th International Conference on Electrical and Electronic Engineering (ICEEE) (IEEE),104-107.

ENEA (2020). Fusione Nucleare. (Accessed May 11, 2020).[Dataset]

European Commission (2020). Critical Infrastructure and Cybersecurity. Available at: https:/ec.europa.eu/energy/topics/energy-security/critical-infrastructureand-cybersecurity_en?redir=1 (Accessed March 23, 2020).

European Smart Grids Task Force (2019a). Final Report-towards Demand Side Flexibility Perceived Barriers and Proposed Recommendations. Available at: https://ec.europa.eu/energy/sites/ener/files/documents/eg3_final_report_demand_ side_flexiblity_2019.04.15.pdf (Accessed March 23, 2020).[Dataset] 
European Smart Grids Task Force (2019b). Final Report-towards Interoperability within the EU for Electricity and Gas Data Access and Exchange. Available at: https://ec.europa.eu/energy/sites/ener/files/documents/eg1_main_report_ interop_data_access.pdf (Accessed March 23, 2020).[Dataset]

Fang, B., Yin, X., Tan, Y., Li, C., Gao, Y., Cao, Y., et al. (2016). The Contributions of Cloud Technologies to Smart Grid. Renew. Sustain. Energ. Rev. 59, 1326-1331. doi:10.1016/j.rser.2016.01.032

Feynman, R. P. (1999). Simulating Physics with Computers. Int. J. Theor. Phys. $21,121$.

Fortune Business Insights (2020). Iot Market Investment. Available at: https://www. fortunebusinessinsights.com/industry-reports/internet-of-things-iot-market100307 (Accessed March 23, 2020).[Dataset]

Geissdoerfer, M., Savaget, P., Bocken, N. M., and Hultink, E. J. (2017). The Circular Economy-A New Sustainability Paradigm?. J. Clean. Prod. 143, 757-768. doi:10.1016/j.jclepro.2016.12.048

Gkatzikis, L., Koutsopoulos, I., and Salonidis, T. (2013). The Role of Aggregators in Smart Grid Demand Response Markets. IEEE J. selected areas Commun. 31, 1247-1257. doi:10.1109/jsac.2013.130708

Gloge, H., der Umwelt, V. z. F., and Energietechnik, e. V, S.-u. (2008). Environmental Comparison of the Relevance of Pc and Thin Client Desktop Equipment for the Climate, 2008. [Dataset].

Good, N., Ellis, K. A., and Mancarella, P. (2017). Review and Classification of Barriers and Enablers of Demand Response in the Smart Grid. Renew. Sustain. Energ. Rev. 72, 57-72. doi:10.1016/j.rser.2017.01.043

Götz, M., Lefebvre, J., Mörs, F., Koch, A. M., Graf, F., Bajohr, S., et al. (2016). Renewable Power-To-Gas: A Technological and Economic Review. Renew. Energ. 85, 1371-1390. doi:10.1016/j.renene.2015.07.066

Hafeez, A., Kandil, N. H., Al-Omar, B., Landolsi, T., and Al-Ali, A. (2014). Smart home Area Networks Protocols within the Smart Grid Context. J. Commun. 9, 665-671. doi:10.12720/jcm.9.9.665-671

Haider, H. T., See, O. H., and Elmenreich, W. (2016). A Review of Residential Demand Response of Smart Grid. Renew. Sustain. Energ. Rev. 59, 166-178. doi:10.1016/j.rser.2016.01.016

Haq, E. U., Xu, H., Pan, L., and Khattak, M. I. (2017). "Smart Grid Security: Threats and Solutions," in 2017 13th International Conference on Semantics, Knowledge and Grids.SKG) (IEEE), 188-193.

Hasani, Z., Kon-Popovska, M., and Velinov, G. (2014). Lambda Architecture for Real Time Big Data Analytic. ICT Innov. 14, 133-143. doi:10.31979/etd.2s5u-hgps

IEA (2017). Digitalization \& Energy. (Accessed March 23, 2020).[Dataset]

IEA (2020). Tracking Energy Integration. Available at: https://www.iea.org/ reports/tracking-energy-integration-2020/smart-grids (Accessed December 02, 2020).[Dataset]

Iqtiyanillham, N., Hasanuzzaman, M., and Hosenuzzaman, M. (2017). European Smart Grid Prospects, Policies, and Challenges. Renew. Sustain. Energ. Rev. 67, 776-790. doi:10.1016/j.rser.2016.09.014

Jaradat, M., Jarrah, M., Bousselham, A., Jararweh, Y., and Al-Ayyoub, M. (2015). The Internet of Energy: Smart Sensor Networks and Big Data Management for Smart Grid. Procedia Comput. Sci. 56, 592-597. doi:10.1016/j.procs.2015.07.250

Jason Verge, T. (2013). Space Weather and the Data Center: The Risk from Solar Storms. Available at: https://www.datacenterknowledge.com/archives/2013/08/ 09/space-weather-and-the-data-center (Accessed March 23, 2020).[Dataset]

Jones, J. A., Mosca, M., and Hansen, R. H. (1998). Implementation of a Quantum Search Algorithm on a Quantum Computer. Nature 393, 344-346. doi:10.1038/30687

Kempton, W., and Tomić, J. (2005). Vehicle-to-grid Power Fundamentals: Calculating Capacity and Net Revenue. J. Power Sourc. 144, 268-279. doi:10.1016/j.jpowsour.2004.12.025

Khatoun, R., and Zeadally, S. (2017). Cybersecurity and Privacy Solutions in Smart Cities. IEEE Commun. Mag. 55, 51-59. doi:10.1109/ mcom. $2017.1600297 \mathrm{~cm}$

King, J. (2018). Energy Impacts of Smart home Technologies. Report A1801.

Ladd, T. D., Jelezko, F., Laflamme, R., Nakamura, Y., Monroe, C., and O’Brien, J. L. (2010). Quantum Computers. Nature 464, 45-53. doi:10.1038/nature08812

Lingam, M., and Loeb, A. (2017). Impact and Mitigation Strategy for Future Solar Flares. Arxiv preprint arXiv:1709.05348

Lomas, K. J., Oliveira, S., Warren, P., Haines, V., Chatterton, T., Beizaee, A., et al. (2018). Do domestic Heating Controls Save Energy? a Review of the Evidence. Renew. Sustain. Energ. Rev. 93, 52-75. doi:10.1016/j.rser.2018.05.002
Lund, H., Werner, S., Wiltshire, R., Svendsen, S., Thorsen, J. E., Hvelplund, F., et al. (2014). 4th Generation District Heating (4gdh): Integrating Smart thermal Grids into Future Sustainable Energy Systems. Energy 68, 1-11. doi:10.1016/ j.energy.2014.02.089

Lund, H., Østergaard, P. A., Connolly, D., and Mathiesen, B. V. (2017). Smart Energy and Smart Energy Systems. Energy 137, 556-565. doi:10.1016/ j.energy.2017.05.123

Marr, B. (2018). How Much Data Do We Create Every Day? The Mind-Blowing Stats Everyone Should Read. Available at: https://www.forbes.com/sites/ bernardmarr/2018/05/21/how-much-data-do-we-create-every-day-the-mindblowing-stats-everyone-should-read/\#23336edf60ba (Accessed March 23, 2020).[Dataset]

Mengelkamp, E., Notheisen, B., Beer, C., Dauer, D., and Weinhardt, C. (2018). A Blockchain-Based Smart Grid: towards Sustainable Local Energy Markets. Comput. Science-Research Dev. 33, 207-214. doi:10.1007/s00450-017-0360-9

Minchala-Avila, L. I., Armijos, J., Pesántez, D., and Zhang, Y. (2016). Design and Implementation of a Smart Meter with Demand Response Capabilities. Energ. Proced. 103, 195-200. doi:10.1016/j.egypro.2016.11.272

Miraz, M. H., Ali, M., Excell, P. S., and Picking, R. (2015). "A Review on Internet of Things (Iot), Internet of Everything (Ioe) and Internet of Nano Things (Iont)," in 2015 Internet Technologies and Applications (ITA). IEEE, 219-224.

Monti, A., Stevic, M., Vogel, S., De Doncker, R. W., Bompard, E., Estebsari, A., et al. (2018). A Global Real-Time Superlab: Enabling High Penetration of Power Electronics in the Electric Grid. IEEE Power Electron. Mag. 5, 134. doi:10.1109/ mpel.2018.2850698

Moriña, D., Serra, I., Puig, P., and Corral, Á. (2019). Probability Estimation of a carrington-like Geomagnetic Storm. Scientific Rep. 9, 1-9. doi:10.1038/s41598019-38918-8

Myers, C. J. (2001). Asynchronous Circuit Design. Hoboken: John Wiley \& Sons.

Mylrea, M. (2017). Smart Energy-Internet-Of-Things Opportunities Require Smart Treatment of Legal, Privacy and Cybersecurity Challenges. The J. World Energ. L. Business 10, 147-158. doi:10.1093/jwelb/jwx001

Nakamoto, S. (2019). Bitcoin: A Peer-To-Peer Electronic Cash System. Tech. Rep. Manubot.

Nambisan, S., Lyytinen, K., Majchrzak, A., and Song, M. (2017). Digital Innovation Management: Reinventing Innovation Management Research in a Digital World. Mis Q. 41, 223-238. doi:10.25300/misq/2017/41:1.03

NASA CubeSat Launch Initiativel (2017). CubeSat 101-Basic Concepts and Processes for First-Time CubeSat Developers. Available at: https://www.nasa. gov/sites/default/files/atoms/files/nasa_csli_cubesat_101_508.pdf (Accessed March 23, 2020).[Dataset]

National Aeronautics and Space Administration - Goddard Space Flight Center (2020). The Impact of Solar Flares. Available at: https://hesperia.gsfc.nasa.gov/ rhessi3/mission/science/the-impact-of-flares/index.html (Accessed March 23, 2020).[Dataset]

Norman, B. (2018). Are Autonomous Cities Our Urban Future?. Nat. Commun. 9, 1-3. doi:10.4324/9781315642482-1

O'Connor, G., and Appzero, W. (2014). Gigaom-Moore's Law Gives Way to Bezos's Law. Available at: https://gigaom.com/2014/04/19/moores-law-givesway-to-bezoss-law/ (Accessed March 23, 2020).[Dataset]

Osseiran, A., Boccardi, F., Braun, V., Kusume, K., Marsch, P., Maternia, M., et al. (2014). Scenarios for $5 \mathrm{~g}$ mobile and Wireless Communications: the Vision of the Metis Project. IEEE Commun. Mag. 52, 26-35. doi:10.1109/ mcom.2014.6815890

Otuoze, A. O., Mustafa, M. W., and Larik, R. M. (2018). Smart Grids Security Challenges: Classification by Sources of Threats. J. Electr. Syst. Inf. Technol. 5, 468-483. doi:10.1016/j.jesit.2018.01.001

Parag, Y., and Sovacool, B. K. (2016). Electricity Market Design for the Prosumer Era. Nat. Energ. 1, 1-6. doi:10.1038/nenergy.2016.32

Patel, P. (2018). How to Convert Your Wall into a Giant Touch Screen. Available at: https://www.scientificamerican.com/article/how-to-convert-your-wall-into-agiant-touch-screen// (Accessed March 23, 2020).[Dataset]

PwC global power and utilities (2015). Blockchain-an Opportunity for Energy Producers and Consumers?. Available at: https://www.pwc.com/gx/en/ industries/assets/pwc-blockchain-opportunity-for-energy-producers-andconsumers.pdf (Accessed March 23, 2020).[Dataset] 
Reka, S. S., and Dragicevic, T. (2018). Future Effectual Role of Energy Delivery: A Comprehensive Review of Internet of Things and Smart Grid. Renew. Sustain. Energ. Rev. 91, 90-108. doi:10.1016/j.rser.2018.03.089

Robu, V., Flynn, D., Andoni, M., and Mokhtar, M. (2019). Consider Ethical and Social Challenges in Smart Grid Research. Nat. Machine Intelligence 1, 548-550. doi:10.1038/s42256-019-0120-6

Ross, W. (2020). Vxchng-Is Your Data Center Prepared for a Natural Disaster?. Available at: https://www.vxchnge.com/blog/is-your-data-center-prepared-fora-natural-disaster (Accessed March 23, 2020).[Dataset]

Saad, W., Bennis, M., and Chen, M. (2019). A Vision of $6 g$ Wireless Systems: Applications, Trends, Technologies, and Open Research Problems. London: IEEE Network.

Schäfer, B., Witthaut, D., Timme, M., and Latora, V. (2018). Dynamically Induced Cascading Failures in Power Grids. Nat. Commun. 9, 1-13. doi:10.1038/s41467018-04287-5

Schieweck, A., Uhde, E., Salthammer, T., Salthammer, L. C., Morawska, L., Mazaheri, M., et al. (2018). Smart Homes and the Control of Indoor Air Quality. Renew. Sustain. Energ. Rev. 94, 705-718. doi:10.1016/j.rser.2018.05.057

Smart Energy International (2017). Over 60 Million Households in Europe Will Have Smart Gas Meters by 2022. Available at: https://www.smart-energy.com/ magazine-article/smart-gas-meters-2022-eu/ (Accessed March 23, 2020). [Dataset]

Soeder, J. F. (2015). Smart Grid Development Issues for Terrestrial and Space Applications. Available at: https://ntrs.nasa.gov/archive/nasa/casi.ntrs.nasa. gov/20150002095.pdf (Accessed March 23, 2020).[Dataset]

Sovacool, B. K., and Del Rio, D. D. F. (2020). Smart home Technologies in Europe: A Critical Review of Concepts, Benefits, Risks and Policies. Renew. Sustain. Energ. Rev. 120, 109663. doi:10.1016/j.rser.2019.109663

Statista (2020). Iot Market. Available at: https://www.statista.com/statistics/ 976313/global-iot-market-size/\#statisticContaine (Accessed January 23, 2020).[Dataset]

Stojkoska, B. L. R., and Trivodaliev, K. V. (2017). A Review of Internet of Things for Smart home: Challenges and Solutions. J. Clean. Prod. 140, 1454-1464. doi:10.1016/j.jclepro.2016.10.006

Strinati, E. C., Barbarossa, S., Gonzalez-Jimenez, J. L., Kténas, D., Cassiau, N., and Dehos, C. (2019). 6g: The Next Frontier. arXiv preprint arXiv: 1901.03239

Strukov, D., Indiveri, G., Grollier, J., and Fusi, S. (2019). Building Brain-Inspired Computing. Nat. Commun. 10, 4838. doi:10.1038/s41467-019-12521-x

Takahashi, T. (2018). Behavioral Economics of Addiction in the Age of a Super Smart Society: Society 5.0. Oukan (J. Transdisciplinary Federation of Sci. Technol.) 12, 119-122. doi:10.4324/9781315643076-9

Tariq, F., Khandaker, M., Wong, K.-K., Imran, M., Bennis, M., and Debbah, M. (2019). A Speculative Study on 6g. arXiv preprint arXiv:1902.06700

Tiefenbeck, V., Wörner, A., Schöb, S., Fleisch, E., and Staake, T. (2019). Real-time Feedback Promotes Energy Conservation in the Absence of Volunteer Selection Bias and Monetary Incentives. Nat. Energ. 4, 35-41. doi:10.1038/s41560-018-0282-1

Tiefenbeck, V. (2017). Bring Behaviour into the Digital Transformation. Nat. Energ. 2, 1-3. doi:10.1038/nenergy.2017.85
Tu, C., He, X., Shuai, Z., and Jiang, F. (2017). Big Data Issues in Smart Grid-A Review. Renew. Sustain. Energ. Rev. 79, 1099-1107. doi:10.1016/j.rser.2017.05.134

Tuballa, M. L., and Abundo, M. L. (2016). A Review of the Development of Smart Grid Technologies. Renew. Sustain. Energ. Rev. 59, 710-725. doi:10.1016/ j.rser.2016.01.011

U.S. Department of Energy (2007). National Energy Technology Laboratory (August 2007). "netl Modern Grid Initiative-Powering Our 21st-century Economy. [Dataset].

Unger, D. J. (2017). Illinois, Smart Thermostats Seen as Key Energy Management Tool. Available at: https://energynews.us/2017/08/01/midwest/in-illinoissmart-thermostats-seen-as-key-energy-management-tool/ (Accessed May 05, 2020).[Dataset]

University of Wollongong (2020). Sustainable Buildings Research Centre. Available at: https://www.uow.edu.au/sbrc/ (Accessed May 11, 2020) [.[Dataset]

Usman, A., and Shami, S. H. (2013). Evolution of Communication Technologies for Smart Grid Applications. Renew. Sustain. Energ. Rev. 19, 191-199. doi:10.1016/j.rser.2012.11.002

Vespignani, A. (2010). The Fragility of Interdependency. Nature 464, 984-985. doi: $10.1038 / 464984 a$

Vinuesa, R., Azizpour, H., Leite, I., Balaam, M., Dignum, V., Domisch, S., et al. (2020). The Role of Artificial Intelligence in Achieving the Sustainable Development Goals. Nat. Commun. 11, 1-10. doi:10.1038/s41467-019-14108-y

Wang, N. N. (2018). Transactive Control for Connected Homes and Neighbourhoods. Nat. Energ. 3, 907-909. doi:10.1038/s41560-018-0257-2

Webborn, E., and Oreszczyn, T. (2019). Champion the Energy Data Revolution. Nat. Energ. 4, 624-626. doi:10.1038/s41560-019-0432-0

Yuan, Y., and Wang, F.-Y. (2016). "Towards Blockchain-Based Intelligent Transportation Systems," in 2016 IEEE 19th International Conference on Intelligent Transportation Systems (ITSC). (IEEE), 2663-2668.

Zheng, Z., Xie, S., Dai, H.-N., Chen, X., and Wang, H. (2018). Blockchain Challenges and Opportunities: A Survey. Int. J. Web Grid Serv. 14, 352-375. doi:10.1504/ijwgs.2018.095647

Zhou, B., Li, W., Chan, K. W., Cao, Y., Kuang, Y., Liu, X., et al. (2016). Smart home Energy Management Systems: Concept, Configurations, and Scheduling Strategies. Renew. Sustain. Energ. Rev. 61, 30-40. doi:10.1016/j.rser.2016.03.047

Conflict of Interest: The authors declare that the research was conducted in the absence of any commercial or financial relationships that could be construed as a potential conflict of interest.

Copyright (๑) 2021 Lo Cascio, Girardin, Ma and Maréchal. This is an open-access article distributed under the terms of the Creative Commons Attribution License (CC $B Y)$. The use, distribution or reproduction in other forums is permitted, provided the original author(s) and the copyright owner(s) are credited and that the original publication in this journal is cited, in accordance with accepted academic practice. No use, distribution or reproduction is permitted which does not comply with these terms. 